Research Article

\title{
Cyclic Performance of Corrugated Steel Plate Shear Walls with Beam-Only-Connected Infill Plates
}

\author{
Seyyed M. Ghodratian-Kashan (iD) and Shervin Maleki \\ Department of Civil Engineering, Sharif University of Technology, Azadi Avenue, Tehran, Iran \\ Correspondence should be addressed to Seyyed M. Ghodratian-Kashan; sm.ghodratian@sharif.edu
}

Received 13 February 2021; Revised 8 June 2021; Accepted 12 July 2021; Published 21 July 2021

Academic Editor: Payam Shafigh

Copyright (c 2021 Seyyed M. Ghodratian-Kashan and Shervin Maleki. This is an open access article distributed under the Creative Commons Attribution License, which permits unrestricted use, distribution, and reproduction in any medium, provided the original work is properly cited.

\begin{abstract}
Lately, Corrugated Steel Plate Shear Walls (CSPSWs) have gained significance and reputation for being effective lateral forceresisting systems. Corrugated plates are characterized by greater out-of-plane stiffness and buckling stability than flat plates, ensuring their enhanced hysteretic behavior. In ordinary Steel Plate Shear Walls (SPSWs), infill plates are fixed to beams and columns. But, detaching the infill plate from columns and connecting it to the beams only is assumed here as a method for reducing column demands. The current study explores the cyclic performance of CSPSWs with beam-only-connected infill plates. The design of a one-story single-bay specimen was done and its finite element model was developed. Parametric studies have targeted CSPSWs with different geometric variables, including orientation, thickness, and aspect ratio of the infill plate. Noteworthy responses were ultimate strength, initial stiffness, energy dissipation capacity, and force-deformation relationship. The obtained results indicated that selecting the right geometrical parameters could yield a desirable cyclic performance. Finally, an analytical method was proposed for calculating the ultimate shear strength of beam-only-connected CSPSWs.
\end{abstract}

\section{Introduction}

Steel Plate Shear Walls (SPSWs) are frequently employed as lateral force-resisting systems in building structures owing to their high stiffness, strength, and ductility. SPSWs are either stiffened and unstiffened in type. Stiffened SPSWs enjoy greater initial stiffness, higher shear strength, and larger ductility than unstiffened ones. However, their fabrication is more expensive and time-consuming because of thin plate welding [1]. Unstiffened SPSWs are of less buckling strength and facilitate shear buckling and the development of diagonal tension field in the panel. Past research on SPSWs without stiffener revealed that the postbuckling strength and ductility of infill plates could be considerable [2-7]. However, unstiffened SPSWs have substantial pinching in hysteresis loops owing to the diagonal tension field effect.

In recent years, researchers have evaluated the possible uses of corrugated plates as SPSW infill plates. Berman and Bruneau [8] scrutinized 3 light-gauge flat and corrugated
SPSWs. The corrugated infill plates were oriented at 45 degrees. As demonstrated by the results, the corrugated specimens suffered a quick loss of strength due to fractures of the infill plate at repeated local buckling locations. In an experimental study, Emami et al. [9] made a comparison between Corrugated Steel Plate Shear Walls (CSPSWs) and Flat Steel Plate Shear Walls (FSPSWs) in terms of cyclic performances. The corrugated plates were placed both horizontally and vertically. The results illustrated that CSPSWs exhibited considerably less pinching in hysteresis loops than FSPSWs because of the greater out-of-plane stiffness and buckling strength of corrugated plates, compared to flat plates. Emami and Mofid's subsequent numerical study on corrugated SPSWs pointed to the conducive role of corrugated plates in improving the steel shear wall performance [10]. Farzampour et al. [11] conducted a numerical study to compare the monotonic behaviors of FSPSW and CSPSW with an opening. Bahrebar et al. [12] carried out a parametric study on CSPSW. They evaluated the effect of infill plate perforation, corrugation 
angle, and infill plate thickness on the performance of CSPSWs under cyclic loading. Cao and Huang [13] performed an experimental and numerical study on two singlebay, two-story CSPSWs under lateral cyclic loads. According to the results, with a proper design of CSPSWs, elastic buckling of infill plates could be avoided, and a tension field would be developed throughout the corrugated plate. Dou et al. [14] studied the shear resistance and postbuckling behavior of sinusoidal CSPSWs through finite element (FE) analysis. Farzampour et al. [15] presented recommendations for the analysis and design of CSPSWs with reduced beam sections. Bahrebar et al. [16] analyzed the cyclic performance of perforated SPSWs with curved corrugated webs. Fang et al. [17] experimentally analyzed the hysteretic behavior of a semirigid frame with a corrugated plate. GhodratianKashan and Maleki [18] conducted a numerical study on a double Corrugated Steel Plate Shear Wall.

The diagonal tension strips exert substantial axial and flexural demands on columns, leading to a condition that makes columns susceptible to premature failure. To decrease column demands in SPSWs, researchers have come up with a number of methods such as offsetting infill plates on each story [1], using an outrigger system in SPSW structures $[19,20]$, using coupling beams to link two SPSWs together [21], perforating infill plates to decrease SPSW stiffness and strength [22], applying low-yield point steel to infill plates [23], using a pin-ended horizontal strut at the midheight of columns on every story [24], utilizing reduced beam sections for the beam-to-column connections $[25,26]$, using a lightgauge plate for infill plate [8], introducing secondary columns as new boundary elements [27], and releasing infill plates from columns and connecting them to the beams only [28-33]. The latter option is of interest in this study.

Besides reducing column demands, beam-only-connected SPSWs have other advantages. The introduction of openings in the infill plate can reduce the shear strength of SPSWs $[11,12]$. In beam-only-connected SPSWs, panels can be fabricated so that there would be a gap between panel edges and the columns, or several panels can be fabricated with a small panel aspect ratio installed parallel to each other in a span. In both cases, an opening space may be easily given adjacent to the column without perforating the infill plate. Moreover, connecting the corrugated infill plate, especially a light-gauge one, to the boundary frame members was found challenging and difficult owing to its thickness and geometry [8], that is, a matter that could prolong the construction time. In the case of beam-only-connected SPSWs, the infill panel can be attached to the frame beams only, while the attachment between the infill panel and columns is ignored.

Xue and $\mathrm{Lu} \mathrm{[28]} \mathrm{investigated} \mathrm{four} \mathrm{twelve-story,} \mathrm{three-}$ bay structures with SPSWs. Their results showed that tension forces on columns due to infill plate tension field action were eliminated when an infill plate was connected only to the beams; therefore, columns experienced less axial and flexural demand, and early failure of columns could be avoided. Choi and Park [29], in an experimental study, compared the cyclic behavior of SPSWs with infill plates connected only to the beams and that with infill plates connected fully to both beams and columns. According to the results, beam-only- connected SPSWs exhibited an outstanding displacement capacity equivalent to that of fully connected SPSWs. However, their stiffness, strength, and energy dissipation capacity decreased. Subsequent experimental and numerical studies of SPSWs with beam-only-connected infill plates demonstrated that these systems had good initial stiffness and lateral strength and considerable ductility and energy dissipation capacity [30, 31]. Clayton et al. [32, 33] studied beam-only-connected infilled plates in self-centering Steel Plate Shear Walls. They showed that beam-only-connected SPSWs had the advantage of reducing column demands.

However, the behavior of CSPSWs with beam-onlyconnected infill plates has not been studied before. This study investigates the feasibility of using corrugated plates as infill plates in beam-only-connected SPSWs. To do so, we modeled and analyzed a one-story single-bay specimen using the commercially available software package ABAQUS [34]. A parametric analysis was employed to investigate the mentioned model by varying its geometry. The parametric study incorporated corrugated plates' orientation (horizontal or vertical), thickness of corrugated plate, and aspect ratio of infill plate. Finally, the analytical equations employed to measure the ultimate strength of beam-onlyconnected CSPSWs are given.

\section{Finite Element Modelling}

A one-story single-bay specimen involving momentresisting beam-to-column connections was initially designed based on the methods given in [1]. Corrugated Steel Plate Shear Walls (CSPSWs) are of relatively smaller ultimate strength than Flat Steel Plate Shear Walls (FSPSWs) with similar thickness and boundary elements [9]. This is due to the accordion characteristic of corrugated plates that reduces the ultimate strength of CSPSWs compared to FSPSWs. Thus, designing boundary elements according to AISC Design Guide 20 [1] would be conservative. After the preliminary design, profiles of the boundary elements (beams and columns) were alleviated, and the resulting specimen was modeled using ABAQUS software to ensure that the modified design had proper behavior (i.e., infill plates yield before beams and beams yield before columns).

Figure 1 shows the dimensions and member sizes of the specimen. In horizontal and vertical CSPSW specimens, corrugation fold lines are, respectively, aligned with beams and columns. The height and length of the specimens are measured to be $1.74 \mathrm{~m}$ and $2.7 \mathrm{~m}$, respectively, from center to center of members. Since this study is a prelude to the experimental cyclic research on corrugated SPSWs with beam-only-connected infill plates and the capacity of hydraulic jacks at the laboratories is limited, it has been decided to use a scaled CSPSW. The model is a half-scale conventional residential building. Specifications of the corrugated plate are given in Figure 2.

ABAQUS, the finite element suite, was employed to develop the models [34]. The models incorporated material and geometrical nonlinearities. The fish plates used to connect the infill panel to the beams and columns were not modeled in the finite element simulation. Such an 


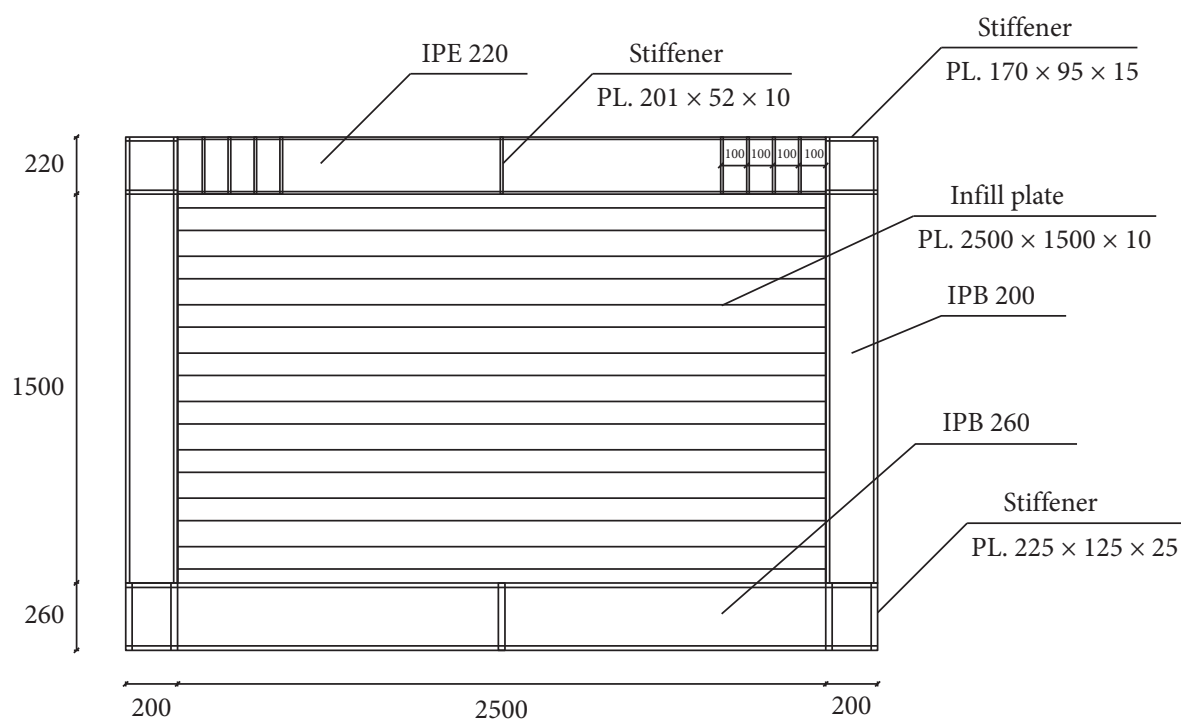

(a)

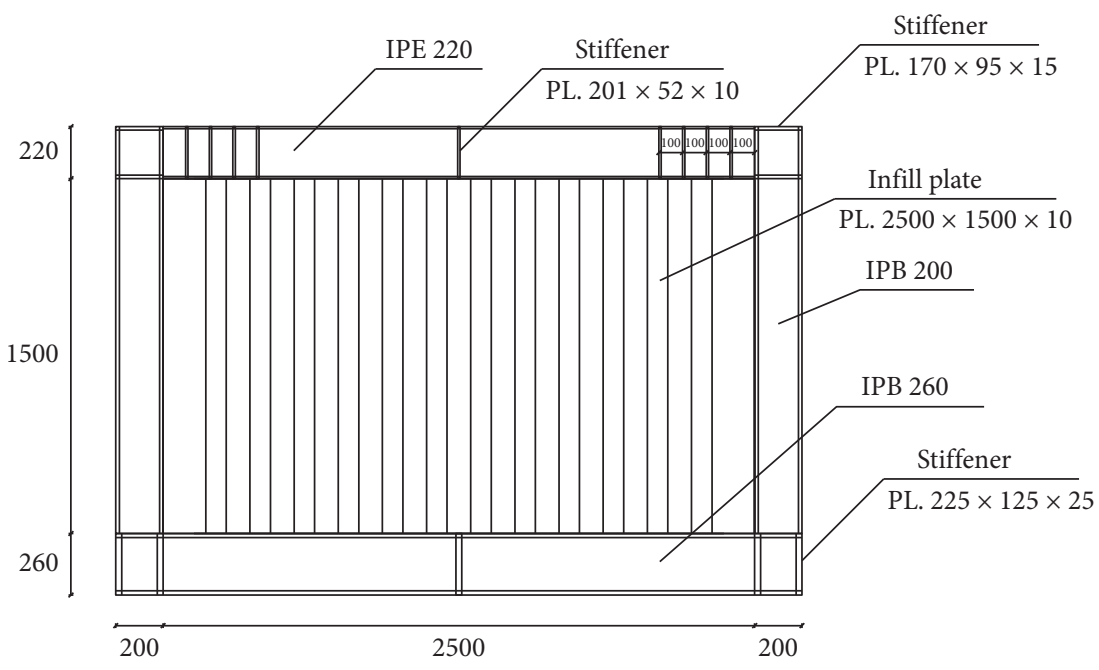

(b)

Figure 1: Specimen's dimensions and member sizes. (a) Horizontal CSPSW. (b) Vertical CSPSW.

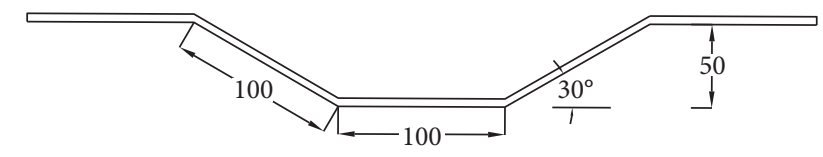

FIgURE 2: Specification of the corrugated plates.

approximation appears to be having a minor impact on the analysis outcome [6]. Components of the boundary frame including beams, columns, and stiffeners as well as corrugated infill panels were modeled through the S4R element, which is a four-node doubly curved general-purpose shell element and is characterized by six degrees of freedom per node with reduced integration and a finite membrane strain. Due to the rigidity of the beam-to-column connections, elements of the shell at intersecting parts were connected directly. "Tie" constraint command was employed to connect the infill plate to the boundary elements. A mesh sensitivity analysis was done on the model [35]. Mesh sizes of $50 \mathrm{~mm}$ and $25 \mathrm{~mm}$ were selected for boundary frame and infill plate, respectively. It should be noted that, according to ABAQUS manual [34], the mesh size of slave parts (infill plate) must be smaller than that of master parts (boundary frame). The type of solver for FE analysis was a static general solver, and the yield criterion was Von Mises. The maximum number of increments and increment sizes were chosen so that convergence problems became minimum. However, some convergence difficulties occurred at maximum displacements in the cyclic loading where the direction of loading changed from positive to negative or vice versa. To solve this problem, "STABILIZE" option was used in the analysis. This option provides volume-proportional damping to the model during nonlinear static analysis. The materials for components of infill plate and boundary frame include St12 and St37 steel in compliance with DIN standard [36], respectively. We adopted the mechanical properties of 
St12 and St37 steel from coupon tests performed by Hosseinzadeh et al. [37] and Jahanpour et al. [27], respectively, as given in Table 1. "Combined hardening," a compound of isotropic and kinematic hardening, was considered for cyclic hardening. In order to determine the cyclic deterioration status, "ductile damage," stress triaxiality dependent fracture initiation criterion, and fracture evolution law in the form of strain softening were added to material modeling [38]. Damage occurred when the DUCTCRT parameter reached 1.0. Linear damage evolution was considered and displacement at failure was $6 \mathrm{~mm}$. Among different failure mechanisms [39], a combination of yielding of the panel under tension and bending failure of horizontal boundary elements was considered as a failure mechanism.

In order to shield the specimen against out-of-plane displacement, as provided by lateral supports in typical test setups, the nodes at the perimeter of the top beam-column connections panel and at the center of the top beam were prevented from translation in the out-of-plane direction. The bottom flange of the beam remained fixed in the model, similar to the boundary conditions set by Emami et al. [9]. Figure 3 lists the usual finite element models for both horizontal and vertical CSPSWs. It is a well-known fact that initial imperfection has a significant influence on the initial stiffness of SPSWs/CSPSWs [40-43]. Initial imperfection was accomplished using "imperfection" command to change the node coordinates. At first, an eigenvalue analysis was done on the FE model using the "buckle" procedure, and buckling mode shapes were derived. Then, deformed shapes corresponding to buckling mode shapes were applied to the FE model with a scale factor. In this study, the initial negligible deformation of $1 \mathrm{~mm}$ was incorporated into the model in line with the model eigenvalue buckling analysis. Figures 4 and 5 show the first buckling mode shape of horizontal CSPSWs (H-CSPSWs) and vertical CSPSWs (VCSPSWs) for fully connected and beam-only-connected states, respectively. To form beam-only-connected SPSWs in ABAQUS, it suffices to eliminate tie constraints between columns and infill plates in the fully connected corrugated SPSWs. The first mode shape of H-CSPSW in both fully connected and beam-only-connected states is global buckling, while that of fully connected and beam-only-connected $\mathrm{V}$-CSPSWs is local buckling.

Given its practicality in typical experiments [9, 25], the vertical load effect was ignored. The models were run at the top beam level horizontally through displacement control based on the history presented in Figure 6. The loading protocol was developed through a combination of ATC-24 [44] protocol and AISC [45] requirements for cyclic loading, similar to previous research works $[25,26]$. To establish the amplitudes of the loading cycle, the parameters of specimen yield need to be determined. Therefore, pushover analysis was applied to the finite element model, and yield displacement and force values were estimated.

Before reaching inelastic behavior, elastic cycles were assigned two displacement amplitudes of one-third and twothirds of the estimated yield displacement. Given that yield drift was approximately measured at $0.3 \%$, these amplitudes corresponded to 0.1 and $0.2 \%$ drift values, respectively.
According to ATC-24 [44], the number of cycles with a peak displacement lower than yield displacement must be six, at least. Therefore, we performed three cycles for each of these drift amplitudes. Three cycles were conducted with respect to the measured yield displacement based on the loading protocol of ATC-24 [44]. Next, an increase in peak displacements was detected due to the estimated ductility of one until a ductility of three was reached. At each peak displacement, cycles were estimated to be three in number. Following this point, cycles at each peak displacement were decreased in number from three to two. Peak displacements were augmented by the estimated ductility of one until reaching an estimated ductility of seven. The estimated ductility of seven was in agreement with a $2.0 \% \mathrm{drift}$. Then, peak displacements were augmented following a $0.5 \% \mathrm{drift}$ increment until reaching $4.0 \% \mathrm{drift}$ as well as $1.0 \%$ increments until reaching a $6.0 \%$ drift. The final loading history is given in Figure 6.

\section{Verification}

For confirming the precision of the finite element model, two experimental test sets were considered for calibration: a flat SPSW tested by Vian et al. [25] and the other set including flat, horizontal corrugated, and vertical corrugated SPSW tested by Emami et al. [9]. Hysteresis curves as well as overall model behavior and failure modes under cyclic loading were compared with their counterparts achieved through the experiments. Figure 7 shows the hysteresis curve of the flat SPSW tested by Vian et al. and the numerical outcomes. Figure 8 shows plastification in the tested model compared to von Mises stress in the FE model at a drift of $3 \%$. The experimental and numerical outcomes obtained from the tested models by Emami et al. are presented in Figure 9 and arranged in Table 2. Substantial consistency between the numerical and test results points to the validity of finite element modeling.

\section{Parametric Study}

To scrutinize the performance of beam-only-connected CSPSWs, a series of parametric researches were performed on specimens, details of which are given in Figure 1. The parametric study includes an orientation of the corrugated plate (horizontal or vertical), infill plate thickness $(t)$, and panel aspect ratio (Ar). Four different thicknesses of the plate including thicknesses less than and equal to $1 \mathrm{~mm}$ (light-gauge plates) as well as four aspect ratios were considered, as shown in Table 3.

4.1. Effect of Corrugated Plate Orientation. Figure 10 shows the hysteresis curves of horizontal CSPSW (H-CSPSW) and vertical CSPSW (V-CSPSW) in both fully connected and beam-only-connected states and bare frame. The thickness and aspect ratio of the infill plate are $1.0 \mathrm{~mm}$ and 1.67 , respectively. According to ATC recommendations [46], the final displacement capacity of specimens must be restricted to deformation corresponding to $80 \%$ of the ultimate strength on the descending branch of the modified backbone curve. The 
TABLE 1: Material mechanical properties.

\begin{tabular}{lccc}
\hline Element $(----)$ & Young's modulus $E(\mathrm{GPa})$ & Yield stress $f y(\mathrm{MPa})$ & Ultimate stress $f u(\mathrm{MPa})$ \\
\hline Plate (ST12) & 200 & 262 & 360 \\
Frame (ST37) & 202 & 280 & 390 \\
\hline
\end{tabular}

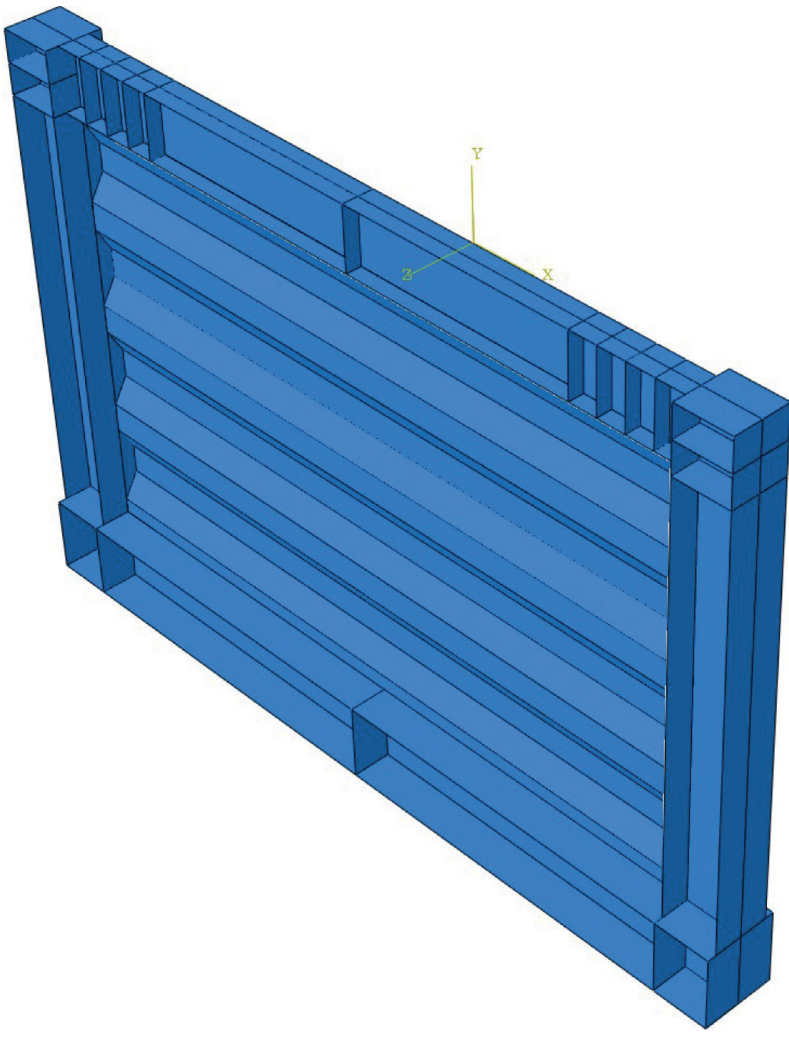

(a)

FIgURe 3: Typical finite element models.

strength loss of $20 \%$ happens following a $3 \%$ drift. Thus, hysteresis curves have been reportedly given up to $3 \%$ drift. The initial stiffness, ultimate strength, and dissipated energy of specimens are arranged in Table 4 . Fully connected H-CSPSW and V-CSPSW have comparable stiffness and strength, as reported in previous studies $[9,10]$. Detaching columns from the infill plate decreased initial stiffness, ultimate strength, and dissipated energy of CSPSWs. In the case of H-CSPSW, detaching columns from the infill plate reduced the initial stiffness from 145.1 to $28.1 \mathrm{MN} / \mathrm{m}$, showing a considerable decrease, and reduced ultimate strength and dissipated energy from 620.3 to $503.6 \mathrm{kN}$ and 382.6 to $311.7 \mathrm{kN}-\mathrm{m}$, respectively. However, in the case of V-CSPSW, detaching columns from the infill plate reduced the initial stiffness from 145.0 to 111.2 MN/m and attenuated the ultimate strength and dissipated energy from 624.7 to $551.4 \mathrm{kN}$ and from 389.1 to $351.6 \mathrm{kN}-\mathrm{m}$, respectively, indicating a lower amount of decrease than that for H-CSPSW. The initial stiffness of the beamonly-connected H-CSPSW is close to that of the bare frame, indicating that infill panel contribution is approximately eliminated at the initial stage of loading due to global buckling.

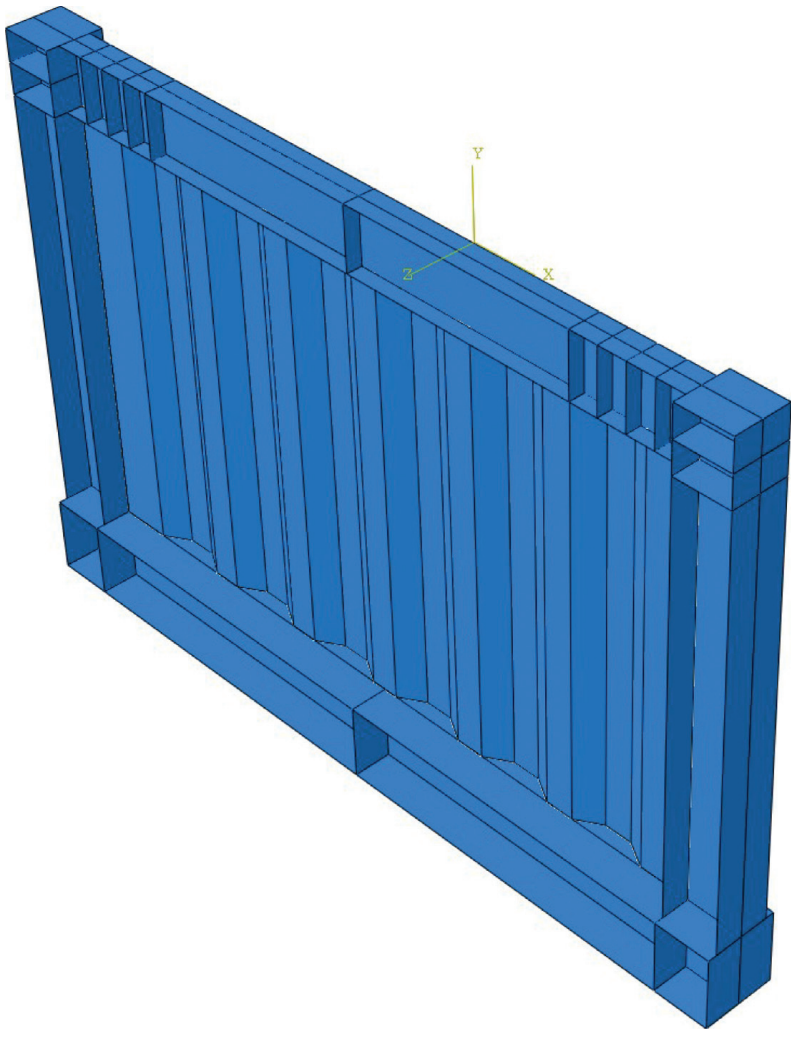

(b)

(a) Horizontal CSPSW. (b) Vertical CSPSW.

Figure 11 shows the maximum in-plane principal stress contour in H-CSPSW for both fully connected and beamonly-connected states at a drift of 3\%. Figure 11(a) shows that the formation of tension strips in the fully connected $\mathrm{H}$-CSPSW depends on both horizontal boundary conditions (beams) and vertical boundary conditions (columns). According to Figure 11(b), detaching columns from the infill plate in H-CSPSW removes the majority of the tension field strips and only one incomplete strip from the bottom left corner to the upper right corner remains in the beam-onlyconnected H-CSPSW. In other words, in the case of fully connected HCSPSW, tension field strips rely on both beams and columns, and releasing columns from the infill plate eliminates the vertical boundary condition, thus removing tension field strips. Eliminating these strips corresponds to the reduction of infill plate contribution and considerably reduces initial stiffness, ultimate strength, and dissipated energy.

The maximum in-plane principal stress contour for fully connected and beam-only-connected V-CSPSWs is illustrated in Figure 12. It can be seen that tension field strips in 


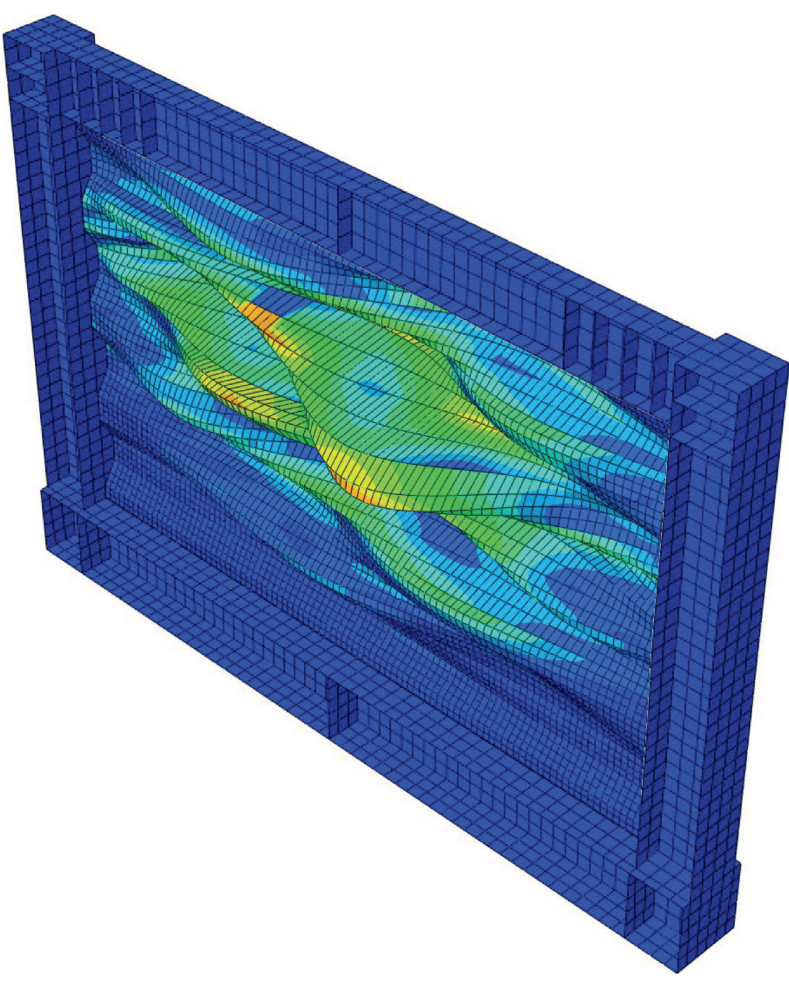

(a)

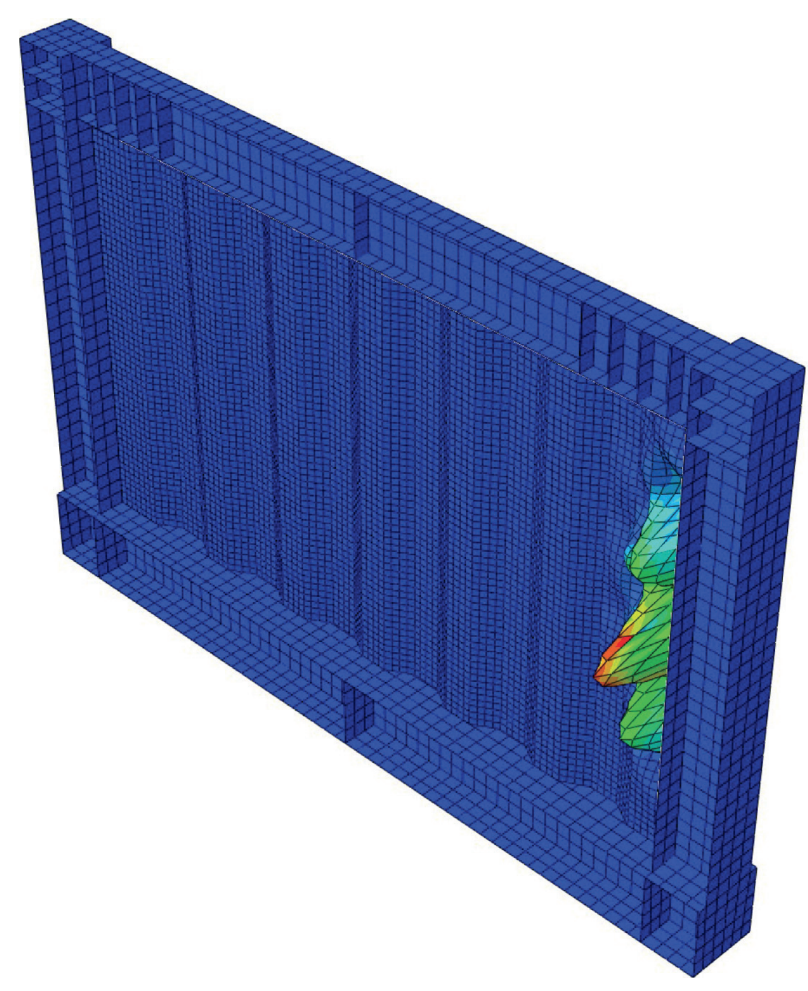

(b)

Figure 4: First mode shape of CSPSWs in the fully connected state. (a) Horizontal CSPSW. (b) Vertical CSPSW.

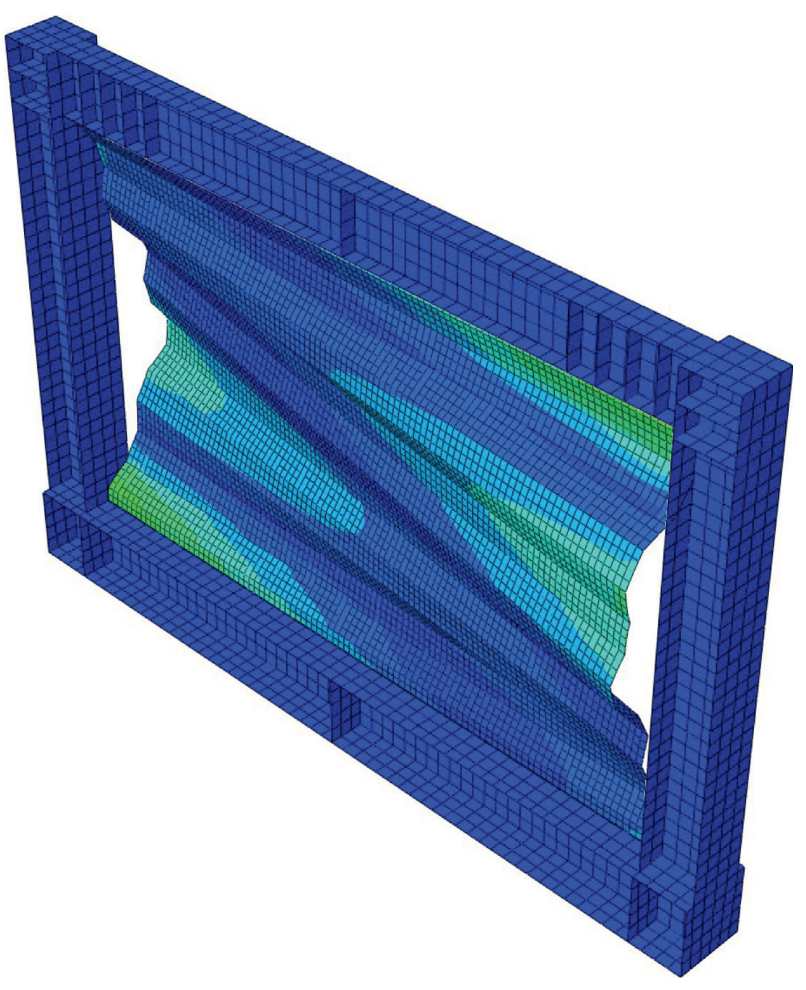

(a)

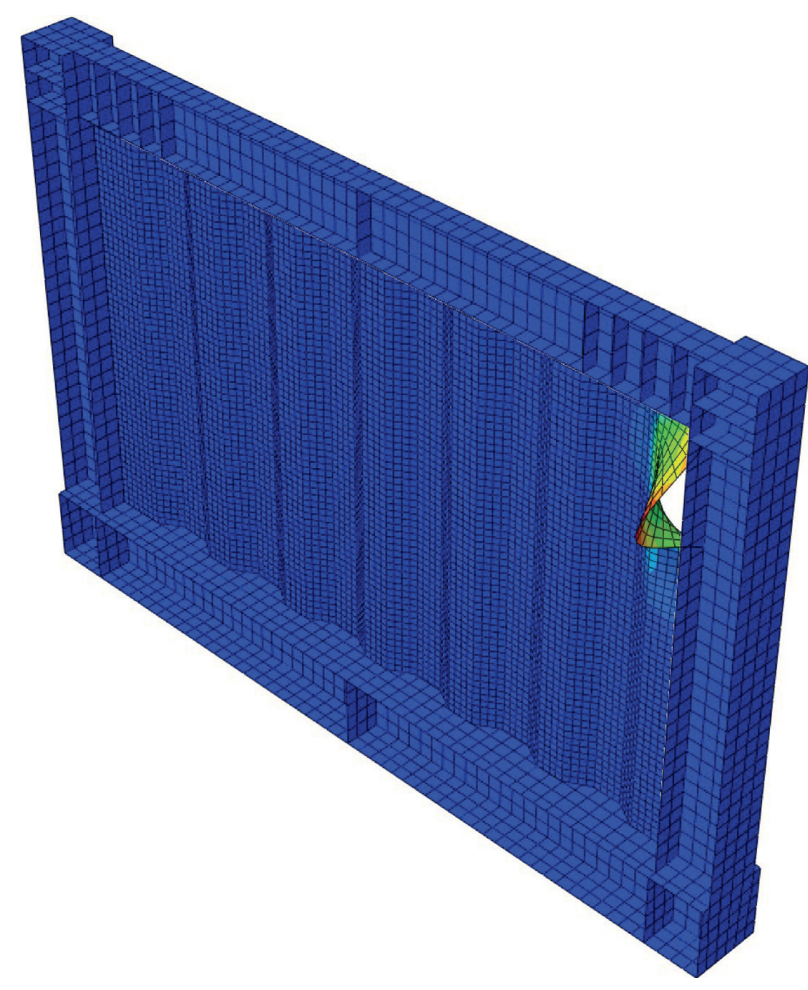

(b)

Figure 5: First mode shape of CSPSWs in the beam-only-connected state. (a) Horizontal CSPSW. (b) Vertical CSPSW. 


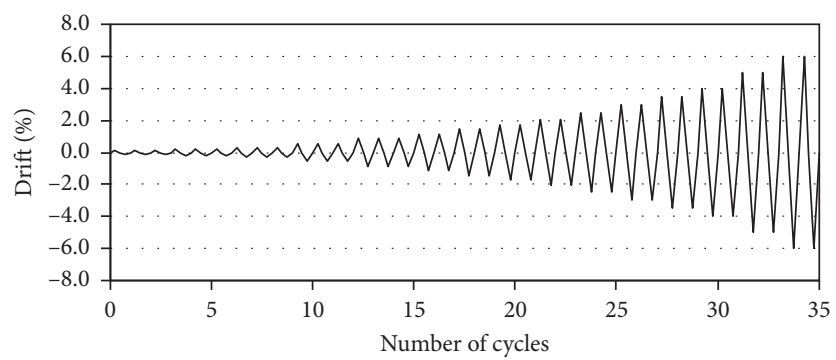

Figure 6: Cyclic loading protocol.

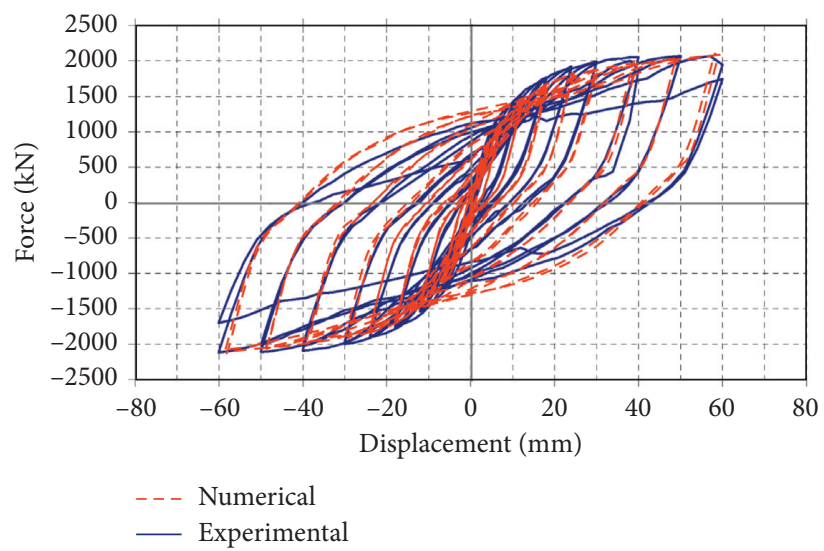

FIGURE 7: Comparison between experimental and computational hysteresis curves for the SPSW tested by Vian et al.

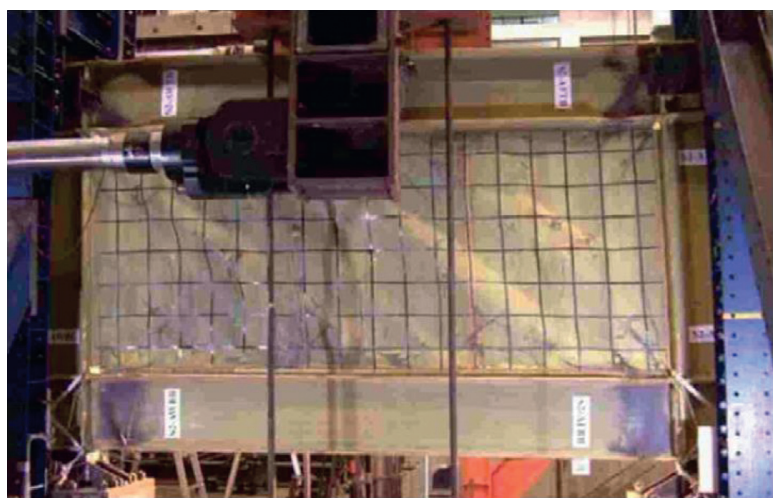

(a)

FIGURE 8: Continued. 
S, mises

SNEG (fraction $=-1.0)$

(Avg: $75 \%)$
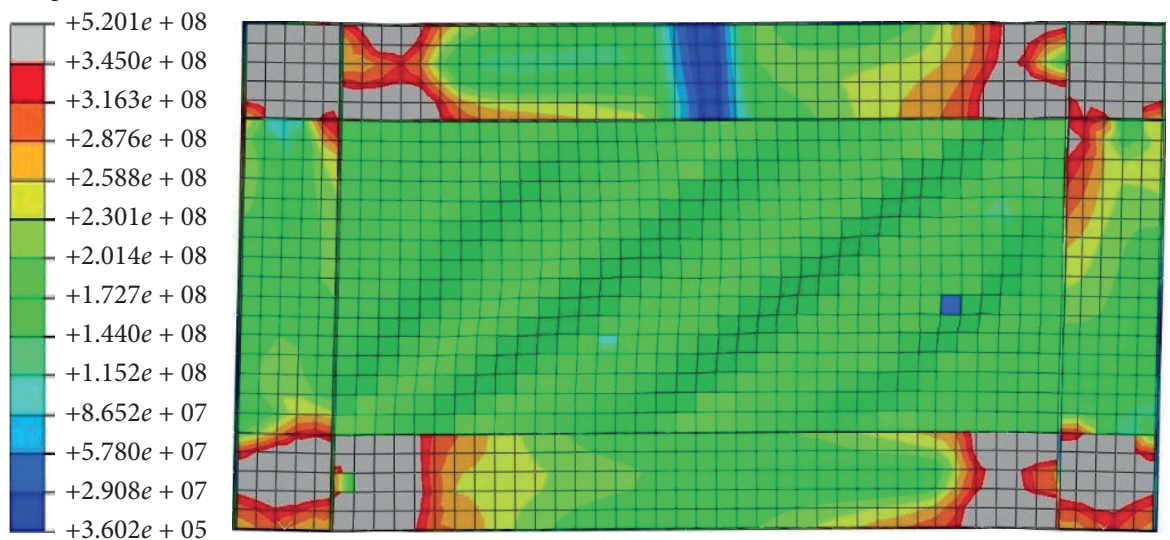

(b)

Figure 8: Comparison between experimental and computational results for von Mises stress at a drift of $3 \%$ for the SPSW tested by Vian et al. (a) Tested model. (b) FE model.

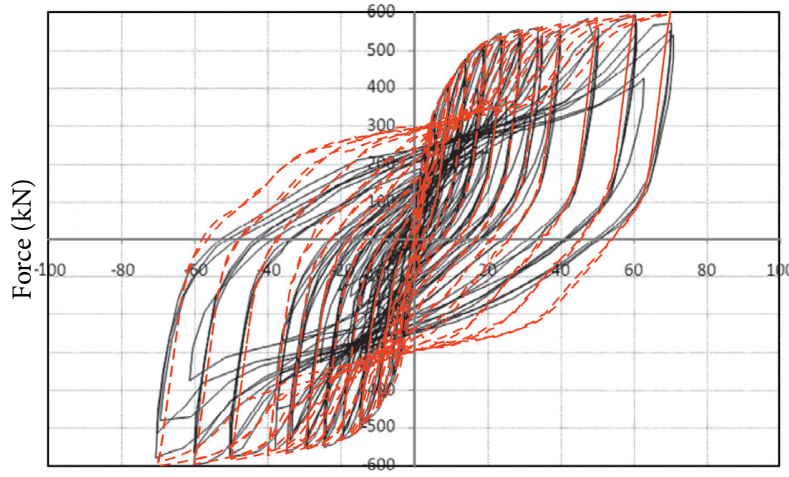

Displacement (mm)

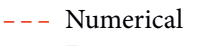

_ Experimental

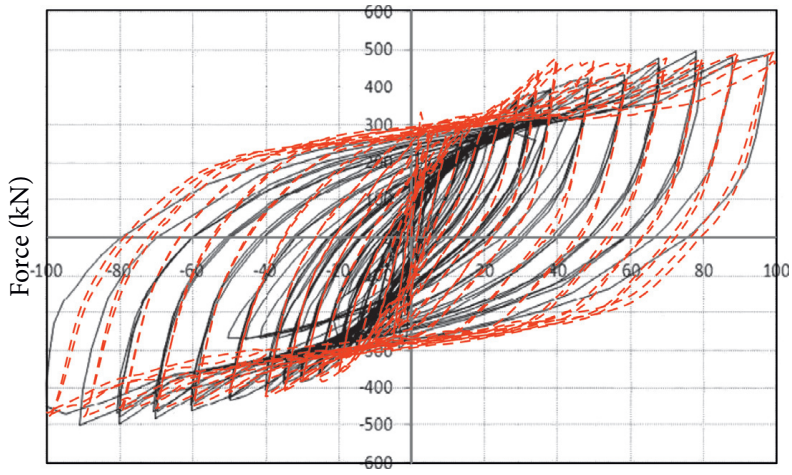

Displacement $(\mathrm{mm})$

- - - Numerical

_ Experimental

(a)

(b)

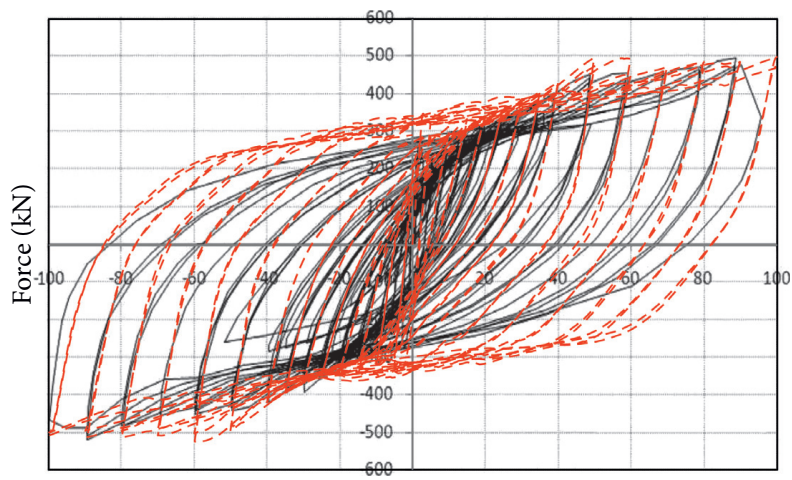

Displacement (mm)

- - - Numerical

_ Experimental

(c)

FIGURE 9: Comparison between experimental and computational results for the SPSWs tested by Emami et al. (a) Flat SPSW. (b) Horizontal corrugated SPSW. (c) Vertical corrugated SPSW. 
TABle 2: Comparison between experimental and analytical results for initial stiffness, ultimate strength, and dissipated energy.

\begin{tabular}{|c|c|c|c|c|c|c|c|c|c|}
\hline & \multicolumn{3}{|c|}{ Initial stiffness $(\mathrm{MN} / \mathrm{m})$} & \multicolumn{3}{|c|}{ Ultimate strength $(\mathrm{kN})$} & \multicolumn{3}{|c|}{ Dissipated energy $(\mathrm{kN}-\mathrm{m})$} \\
\hline & Exp. & Num. & Exp./num. & Exp. & Num. & Exp./num. & Exp. & Num. & Exp./num. \\
\hline FSPSW & 108 & 110.8 & 0.98 & 597 & 599.6 & 1.00 & 589.3 & 613.9 & 0.96 \\
\hline HCSPSW & 130 & 133.1 & 0.98 & 502 & 492.7 & 1.02 & 974.4 & 1015.0 & 0.96 \\
\hline VCSPSW & 125 & 131.3 & 0.95 & 498 & 524.5 & 0.95 & 1104.9 & 1163.0 & 0.95 \\
\hline
\end{tabular}

TABLE 3: Variations of CSPSW parameters.

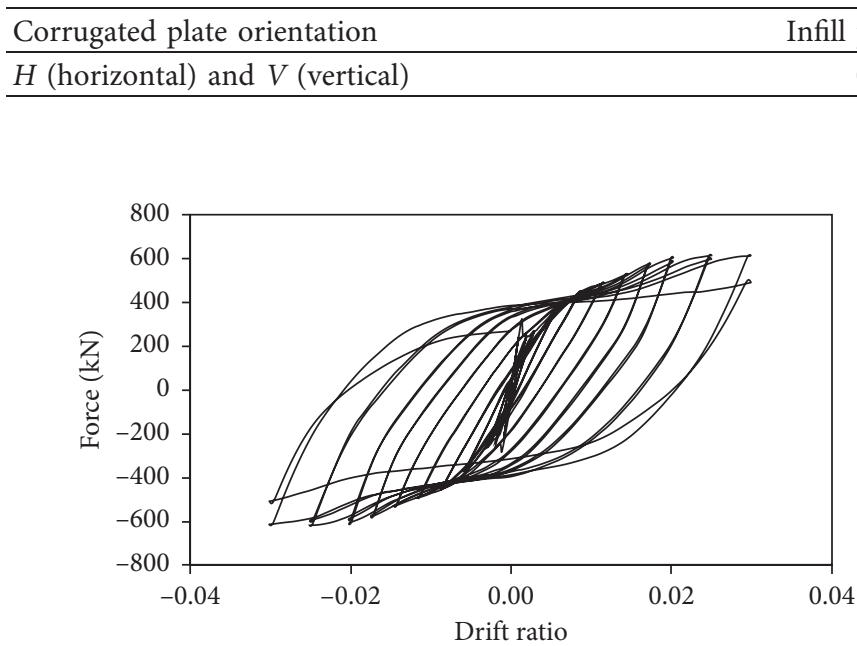

(a)

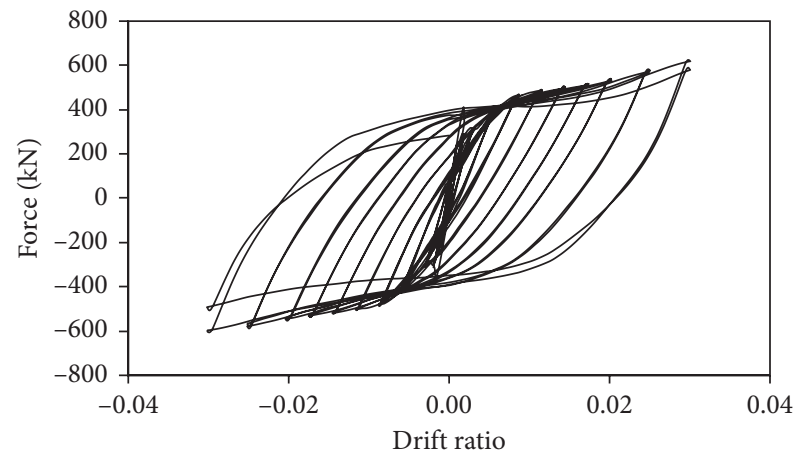

(c)

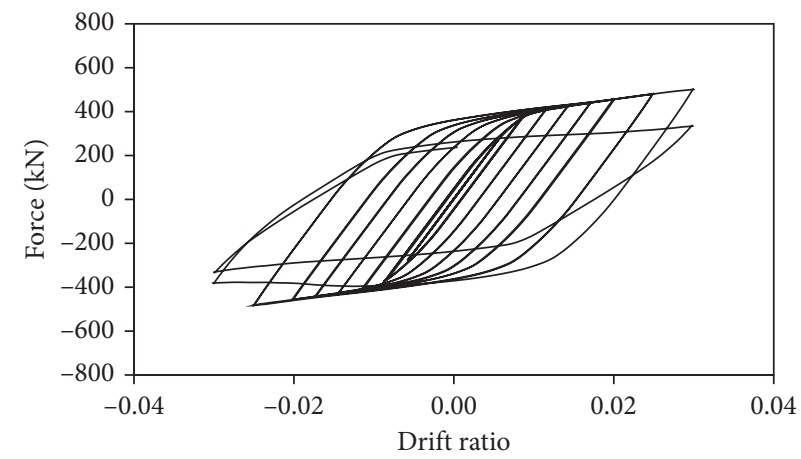

(b)

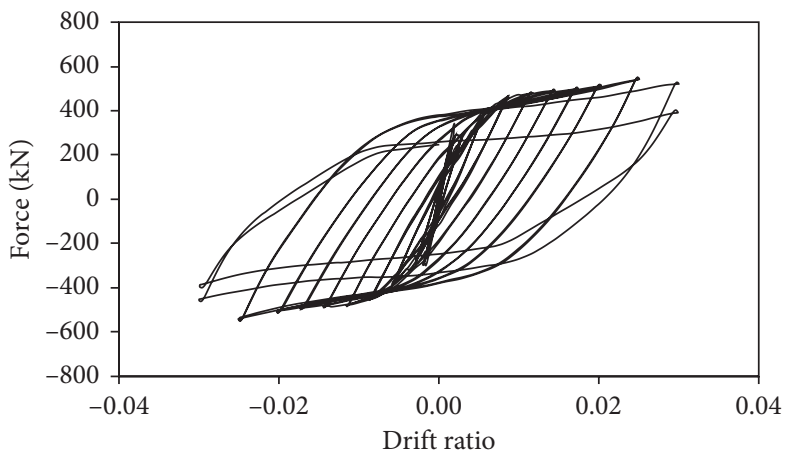

(d)

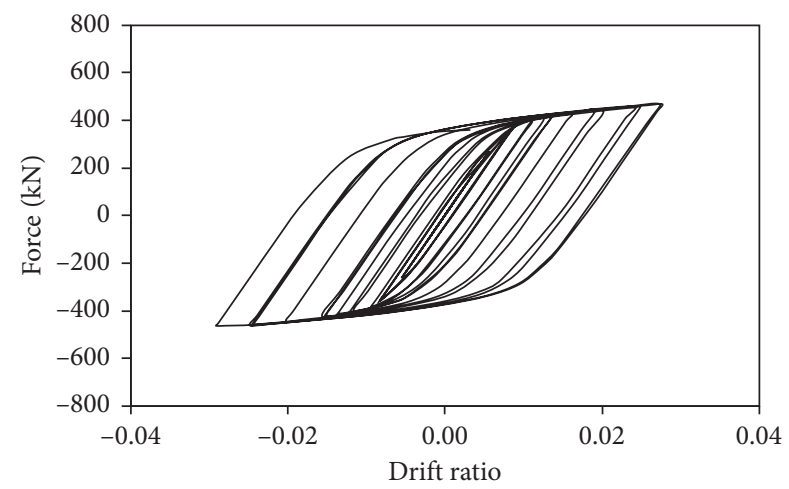

(e)

FIGURE 10: Hysteresis curves of CSPSWs with different configurations. (a) Fully connected H-CSPSW. (b) Beam-only-connected H-CSPSW. (c) Fully connected V-CSPSW. (d) Beam-only-connected V-CSPSW. (e) Bare frame. 
TABLE 4: Initial stiffness and ultimate strength for specimens.

\begin{tabular}{|c|c|c|c|c|c|}
\hline \multirow{2}{*}{ Parameter } & \multicolumn{2}{|c|}{ H-CSPSW } & \multicolumn{2}{|c|}{ V-CSPSW } & \multirow{2}{*}{ Bare frame } \\
\hline & Fully connected & Beam-only-connected & Fully connected & Beam-only-connected & \\
\hline Initial stiffness $(\mathrm{MN} / \mathrm{m})$ & 145.1 & 28.1 & 145.0 & 111.2 & 27.7 \\
\hline Ultimate strength $(\mathrm{kN})$ & 620.3 & 503.6 & 624.7 & 551.4 & 465.3 \\
\hline Dissipated energy $(\mathrm{kN}-\mathrm{m})$ & 382.6 & 311.7 & 389.1 & 351.6 & 288.4 \\
\hline
\end{tabular}

$S$, max. in-plane principal

SNEG (fraction $=-1.0$ )

(Avg: 75\%)

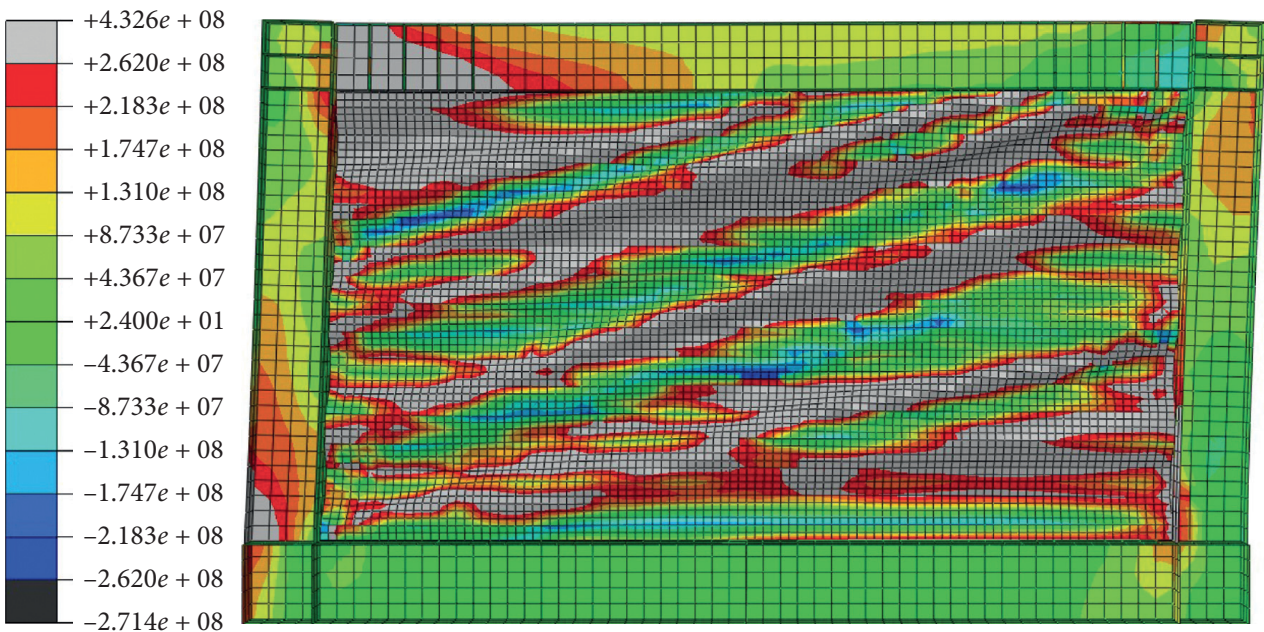

(a)

$S$, max. in-plane principal

SNEG $($ fraction $=-1.0$ )

(Avg: 75\%)

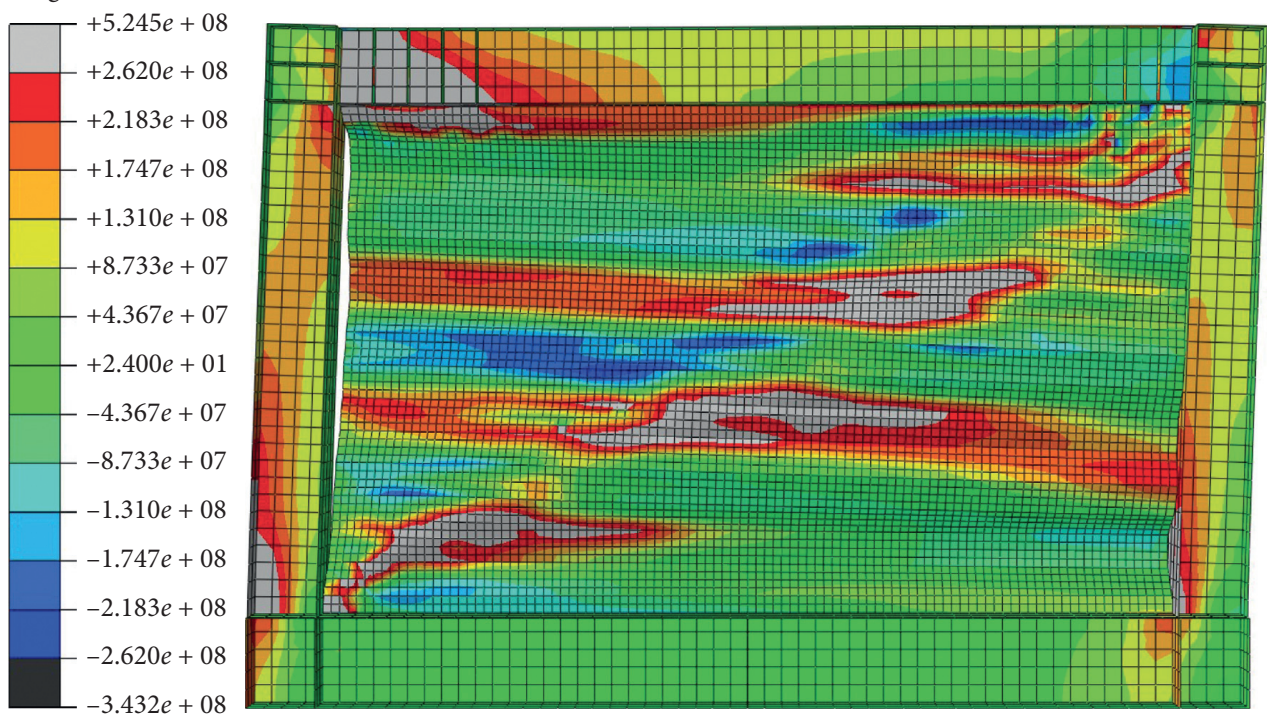

(b)

FIGURE 11: Maximum in-plane principal stress contours in H-CSPSW. (a) Fully connected H-CSPSW. (b) Beam-only-connected H-CSPSW. 


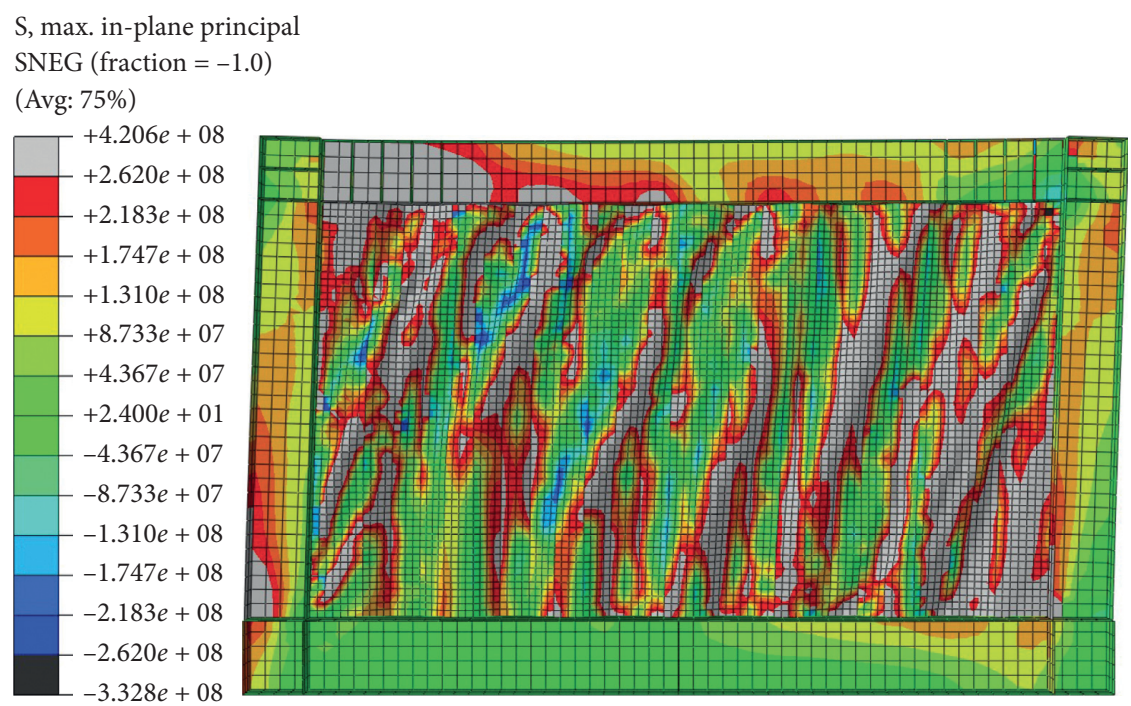

(a)

S, max. in-plane principal

SNEG (fraction $=-1.0)$

(Avg: $75 \%$ )

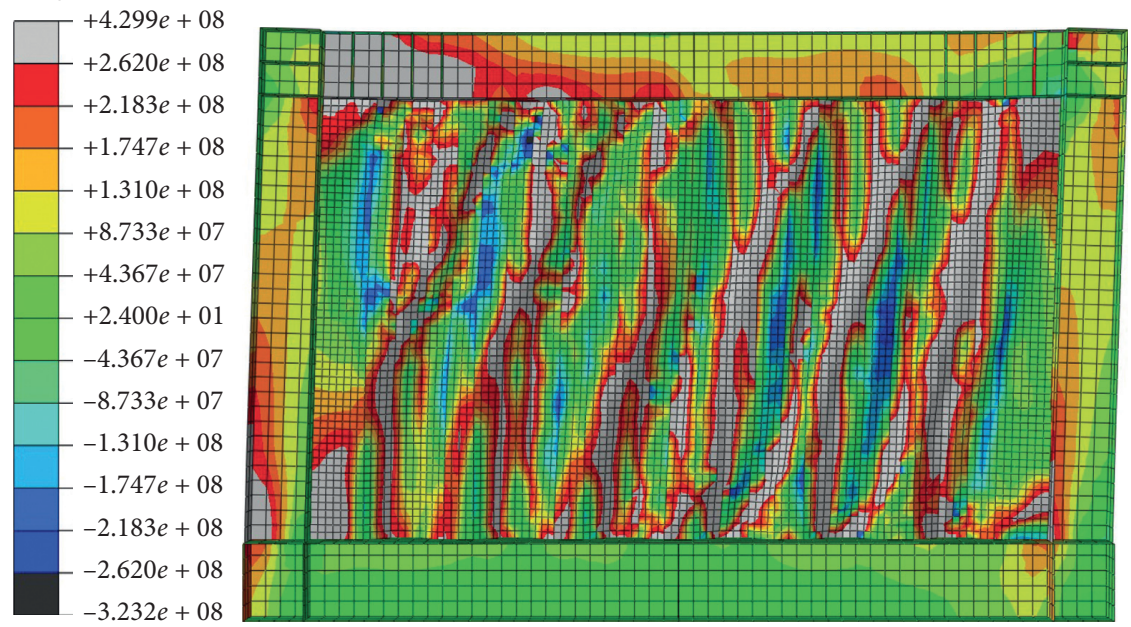

(b)

FIGURE 12: Maximum in-plane principal stress contours in V-CSPSW. (a) Fully connected V-CSPSW. (b) Beam-only-connected V-CSPSW.

the fully connected V-CSPSW rely heavily on horizontal boundary condition than vertical boundary condition and releasing columns from infill plate removes only some tension field strips while the major part of the infill plate contribution remains. It is implied that the beam-onlyconnected V-CSPSW outperforms the beam-only-connected $\mathrm{H}$-CSPSW.

4.2. Effect of Infill Plate Thickness. This section is devoted to investigating the impact of the thickness of the infill plate on the cyclic behavior of beam-only-connected CSPSWs. Performances of the corrugated CSPSWs with both horizontal and vertical corrugation orientations with $t=0.5,1.0,1.5$, and $2.0 \mathrm{~mm}$ were evaluated. The aspect ratio was 1.67 . The cyclic performances of the beam-only-connected horizontal and vertical CSPSWs are presented in Figures 13 and 14, respectively.

From Figure 13, it can be seen that H-CSPSWs with different thicknesses have approximately similar behavior. The reason is that the H-CSPSWs experience early global buckling (Figure 5(a)) and this behavior puts off the formation of tension field strips. This delay reduces the contribution of the infill plate to the H-CSPSW stiffness and ultimate strength, and the cyclic behavior of the boundary frame dominates the overall performance of the H-CSPSW. However, in V-CSPSWs, early global buckling does not occur, and tension strips are derived from the initial stage of loading. Thus, the increase in strength occurs from the very beginning of loading, according to Figure 14.

The responses of H-CSPSW and V-CSPSW as functions of infill plate thickness are given in Figures 15(a)-15(c). It is 


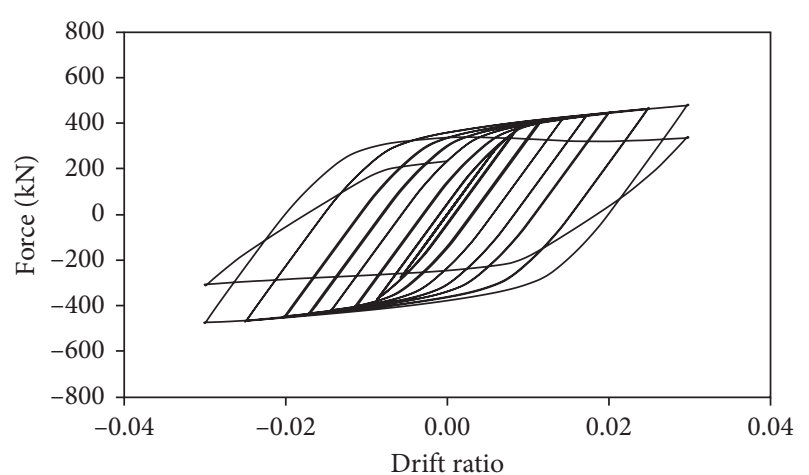

(a)

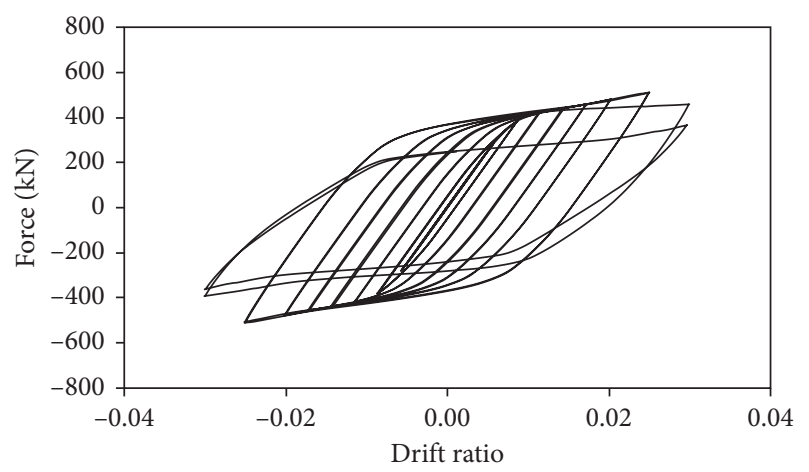

(c)

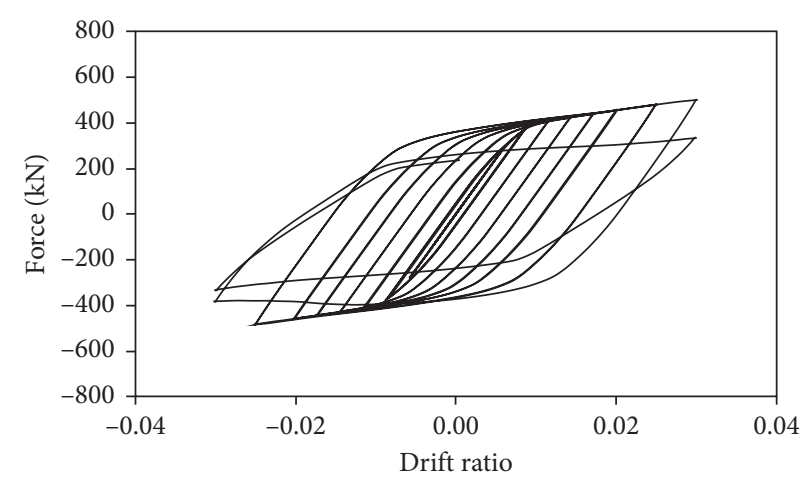

(b)

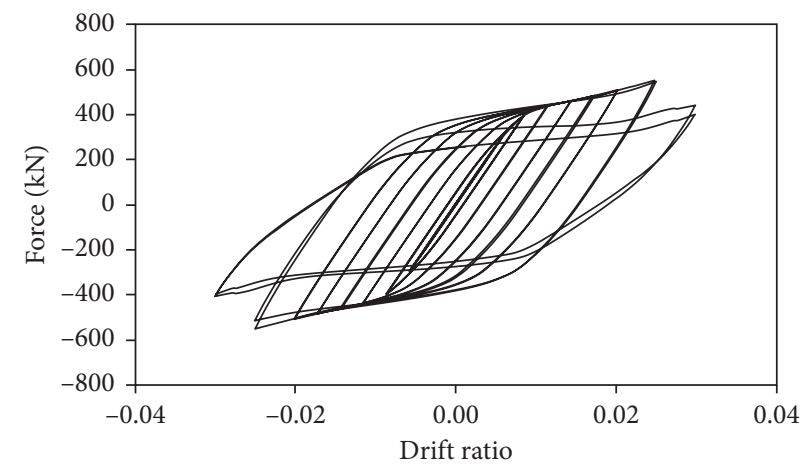

(d)

Figure 13: Hysteresis curves of beam-only-connected H-CSPSWs for different plate thicknesses. (a) $t=0.5 \mathrm{~mm}$. (b) $t=1.0 \mathrm{~mm}$. (c) $t=1.5 \mathrm{~mm}$. (d) $t=2.0 \mathrm{~mm}$.

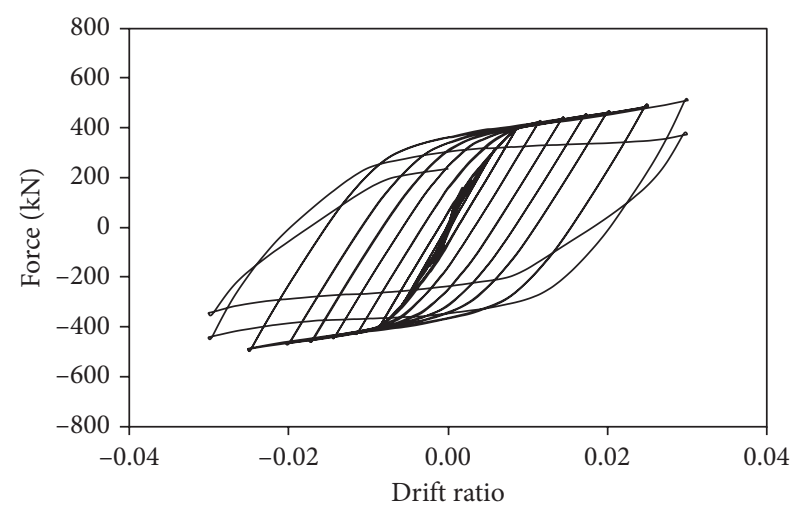

(a)

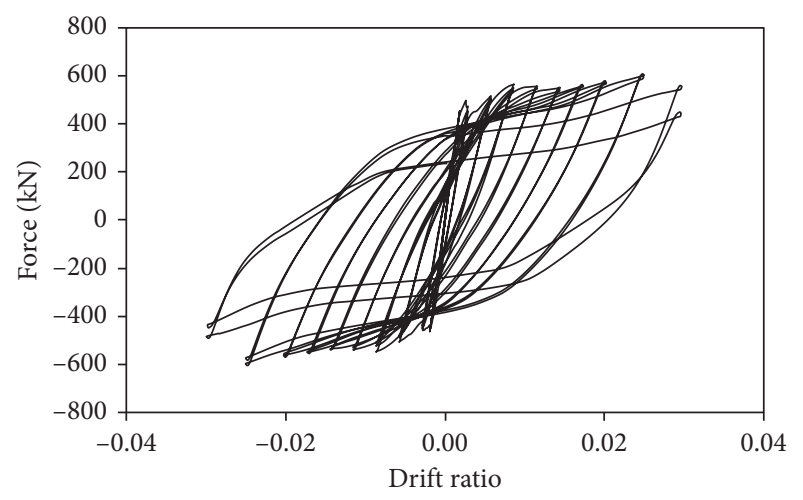

(c)

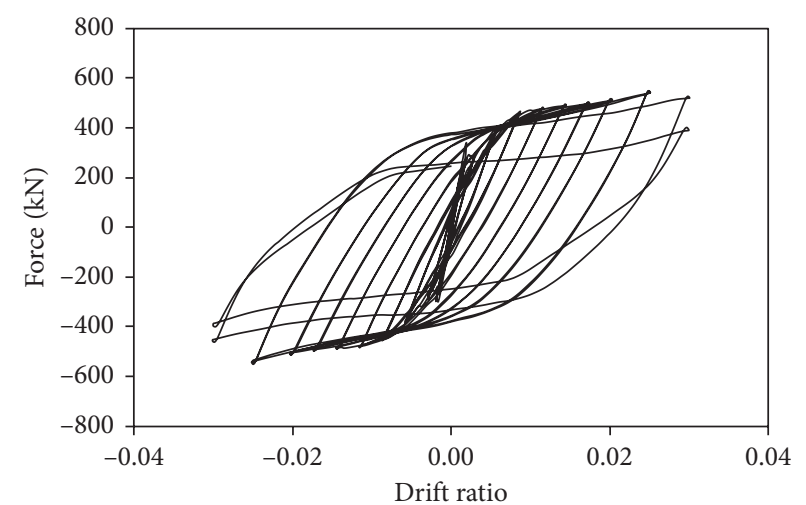

(b)

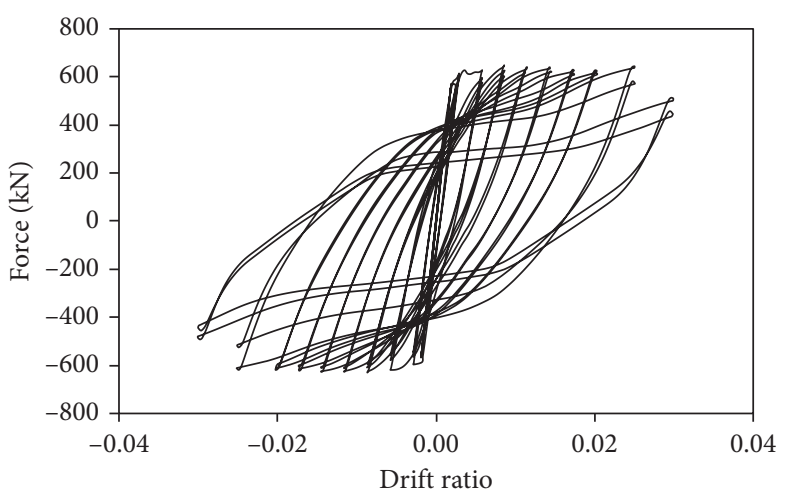

(d)

Figure 14: Hysteresis curves of beam-only-connected V-CSPSWs for different plate thicknesses. (a) $t=0.5 \mathrm{~mm}$. (b) $t=1.0 \mathrm{~mm}$. (c) $t=1.5 \mathrm{~mm}$. (d) $t=2.0 \mathrm{~mm}$. 


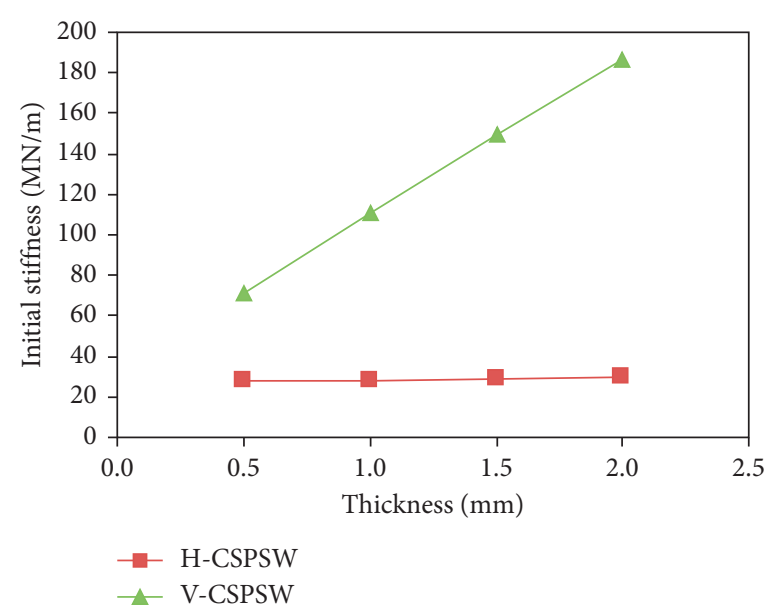

(a)

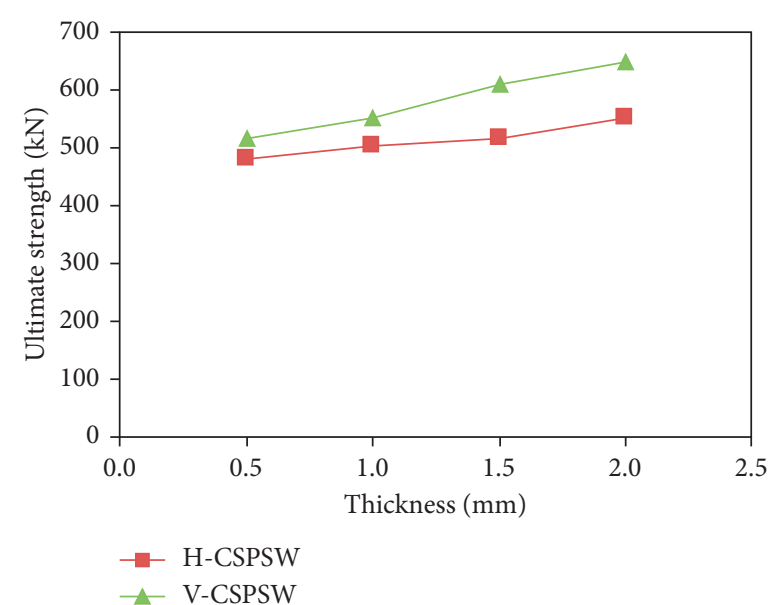

(b)

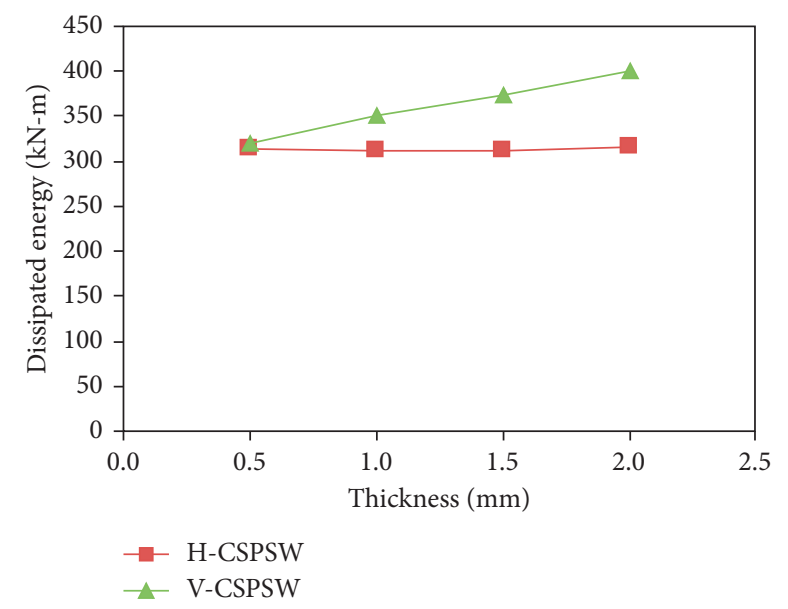

(c)

FIgURE 15: The responses of H-CSPSWs and V-CSPSWs as functions of infill plate thickness. (a) Initial stiffness. (b) Ultimate strength. (c) Dissipated energy.

clear that initial stiffness, ultimate strength, and energy dissipation for H-CSPSW are approximately constant for different thicknesses due to the dominant behavior of the boundary frame in the system performance. However, for V-CSPSW, initial stiffness, ultimate strength, and energy dissipation increase in proportion to the infill plate thickness. In the case of V-CSPSW, increasing infill plate thickness from $0.5 \mathrm{~mm}$ to $2.0 \mathrm{~mm}$ increases initial stiffness, ultimate strength, and dissipated energy from 71.2 to $186.6 \mathrm{MN} / \mathrm{m}, 516.9$ to $647.5 \mathrm{kN}$, and 320.2 to $400.4 \mathrm{kN}-\mathrm{m}$, respectively. Thus, V-CSPSW has better performance than H-CSPSW, especially for the larger thickness. Of note, increasing the thickness of the infill plate can yield higher demands on horizontal boundary frame members, that is, beams, and this should be incorporated in the design.

4.3. Effect of Panel Aspect Ratio. In this section, the influence of panel aspect ratio (Ar) on the cyclic performance of beamonly-connected CSPSWs is investigated. To delve into various panel aspect ratios, the panel height remained constant, equal to $1500 \mathrm{~mm}$, and the length of the panel changed. Frame members, that is, beams and columns, were designed for different aspect ratios. Panel aspect ratios and frame members are summarized in Table 5 . The hysteresis curves of the beam-only-connected horizontal and vertical CSPSWs with $t=1 \mathrm{~mm}$ are shown in Figures 16 and 17, respectively.

From Figures 16 and 17, it can be concluded that any increase in the panel aspect ratio from 1.00 to 3.00 will be productive in improving the cyclic performance of the beam-only-connected CSPSWs. In fact, an increase in the panel aspect ratio causes an increase in the number of tension field strips formed at the infill panel and also causes an increase in frame member profiles, thus resulting in more significant initial stiffness, ultimate strength, and dissipated energy.

The responses of H-CSPSW and V-CSPSW as functions of panel aspect ratio are presented in Figures 18(a)-18(c). According to Figure 18(a), the initial stiffness of H-CSPSW is approximately constant with a panel aspect ratio. However, the initial stiffness for V-CSPSW increases 
TABLE 5: Panel aspect ratios.

\begin{tabular}{|c|c|c|c|c|}
\hline Ar, panel aspect ratio & $H$, height of panel $(\mathrm{mm})$ & $L$, lLength of panel $(\mathrm{mm})$ & Beam profile & Column profile \\
\hline 1.00 & 1500 & 1500 & IPE 200 & IPB 180 \\
\hline 1.67 & 1500 & 2500 & IPE 220 & IPB 200 \\
\hline 2.33 & 1500 & 3500 & IPE 240 & IPB 220 \\
\hline 3.00 & 1500 & 4500 & IPE 270 & IPB 240 \\
\hline
\end{tabular}

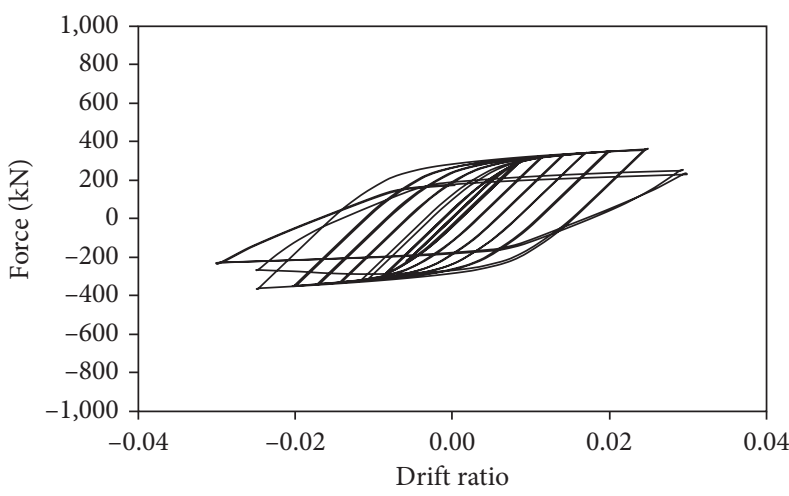

(a)

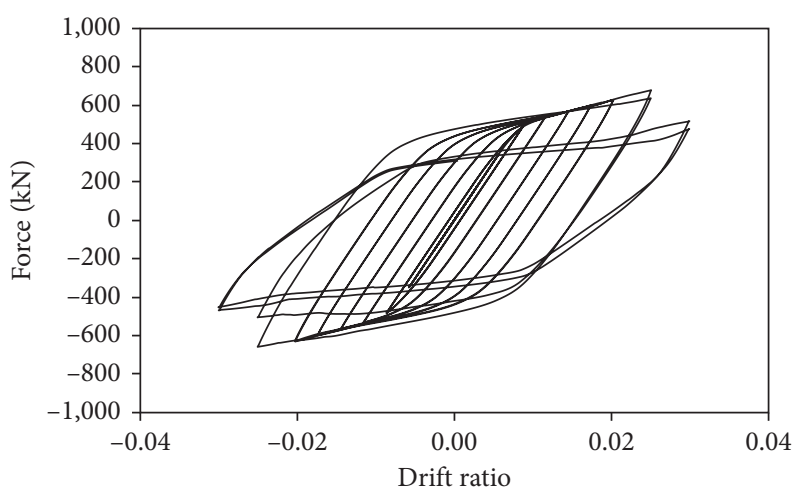

(c)

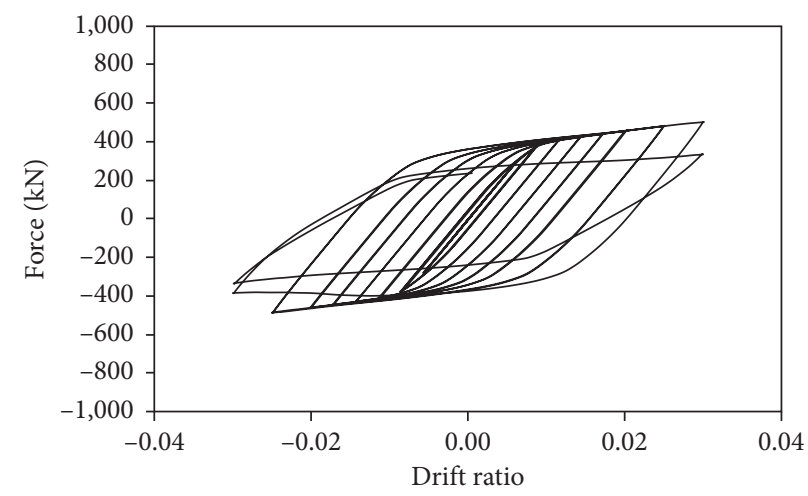

(b)

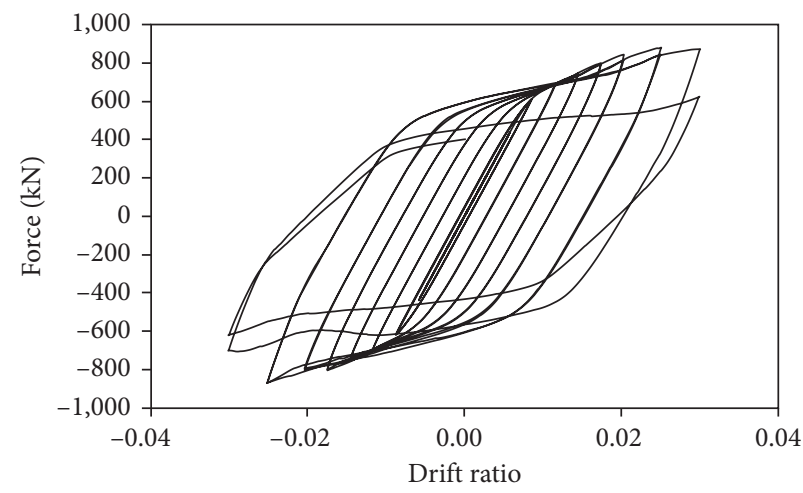

(d)

FiguRE 16: Hysteresis curves of beam-only-connected H-CSPSWs at different panel aspect ratios. (a) $\mathrm{Ar}=1.00 .(\mathrm{b}) \mathrm{Ar}=1.67$. (c) $\mathrm{Ar}=2.33$. (d) $\mathrm{Ar}=3.00$.

proportional to the panel aspect ratio. From Figures 18(b) and 18(c), the larger panel aspect ratio increases the ultimate strength and dissipated energy for both H-CSPSW and V-CSPSW.

\section{Ultimate Strength of Beam-Only- Connected CSPSWs}

The ultimate shear strength of beam-only-connected CSPSWs can be estimated through the following equation [15]:

$$
F_{s u}=F_{f u}+F_{p t},
$$

where $F_{s u}$ is the final shear strength of the Steel Plate Shear Wall, $F_{f u}$ is the strength of the bare frame, and $F_{p t}$ is the strength of the plate. $F_{f u}$ is given by the following equation [15]:

$$
F_{f u}=\frac{4 M_{p}}{h_{s}}
$$

where $M_{p}$ is the lowest plastic moment capacity of the beam and columns and $h_{s}$ is the specimen's height.

It should be noted that, in beam-only-connected CSPSWs, a partial tension field develops over the definite length of the infill plate (Figure 19). In this study, this definite length is introduced to be an effective length $L_{\text {eff }}$ and is proposed to be calculated by the following equation:

$$
L_{\text {eff }}=L-h \cot \theta
$$

where $L$ and $L_{\text {eff }}$ are the length and effective length of the infill plate, respectively. $h$ is the height of the infill plate, and $\theta$ is the tension field inclination angle measured with respect to the horizontal axis. The angle is suggested to be 30 degrees for horizontal CSPSW and 60 degrees for vertical CSPSW 


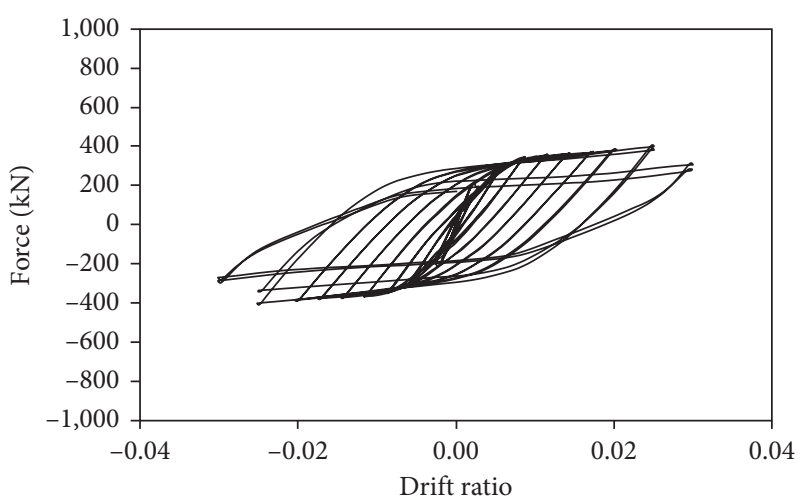

(a)

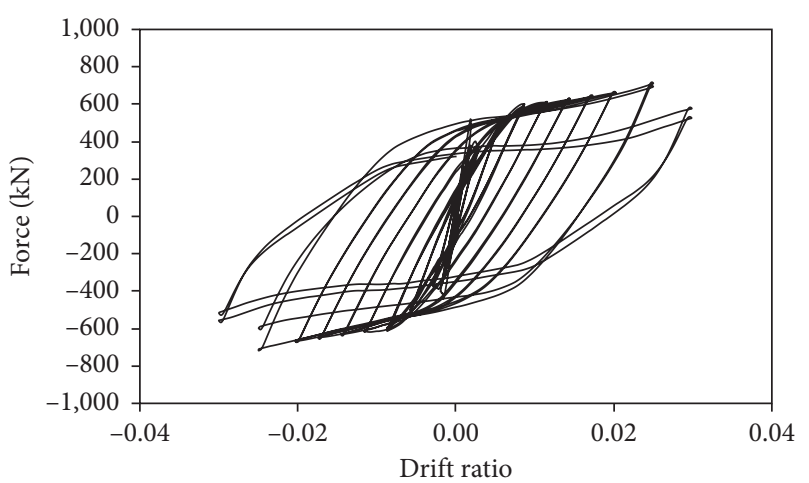

(c)

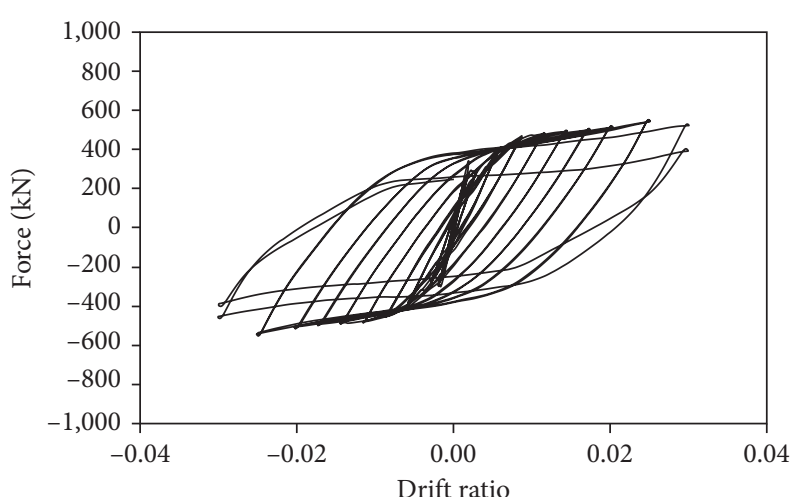

(b)

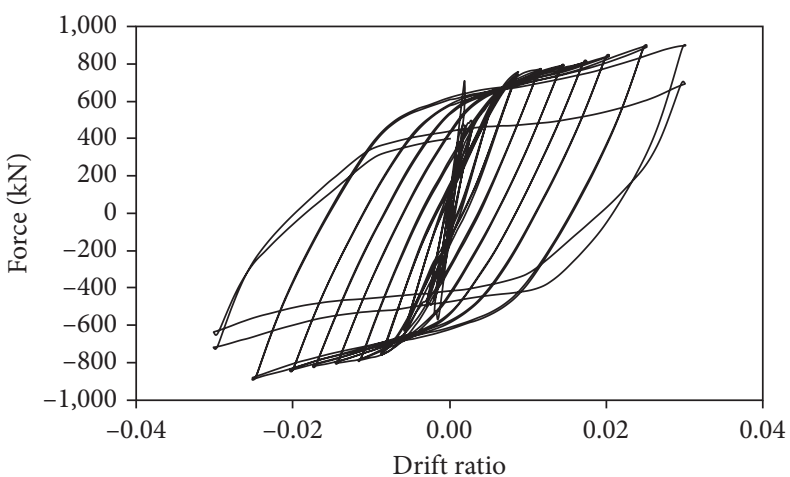

(d)

Figure 17: Hysteresis curves of beam-only-connected V-CSPSW at different panel aspect ratios. (a) $\mathrm{Ar}=1.00$. (b) $\mathrm{Ar}=1.67$. (c) $\mathrm{Ar}=2.33$. (d) $\mathrm{Ar}=3.00$.

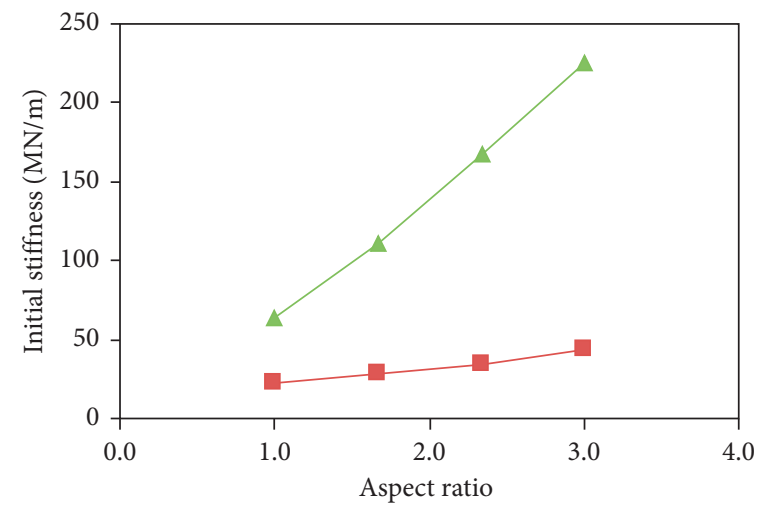

$\rightarrow-\mathrm{H}-\mathrm{CSPSW}$

$\rightarrow$ V-CSPSW

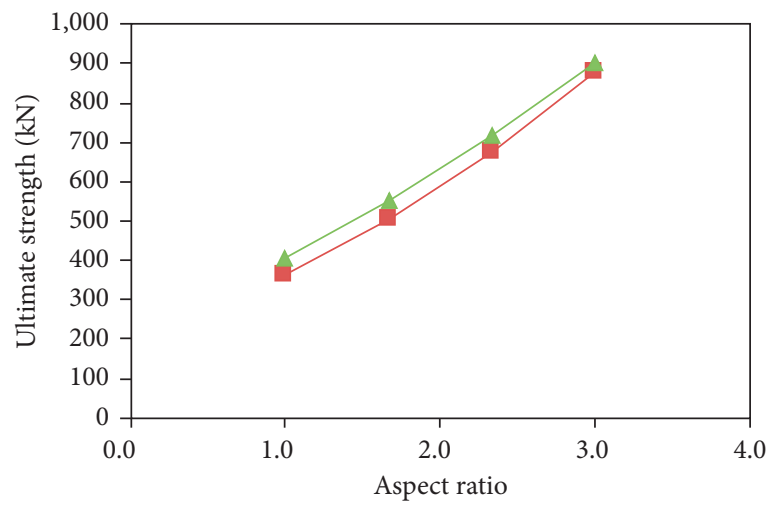

- H-CSPSW

- V-CSPSW

(a)

(b)

FIGURE 18: Continued. 


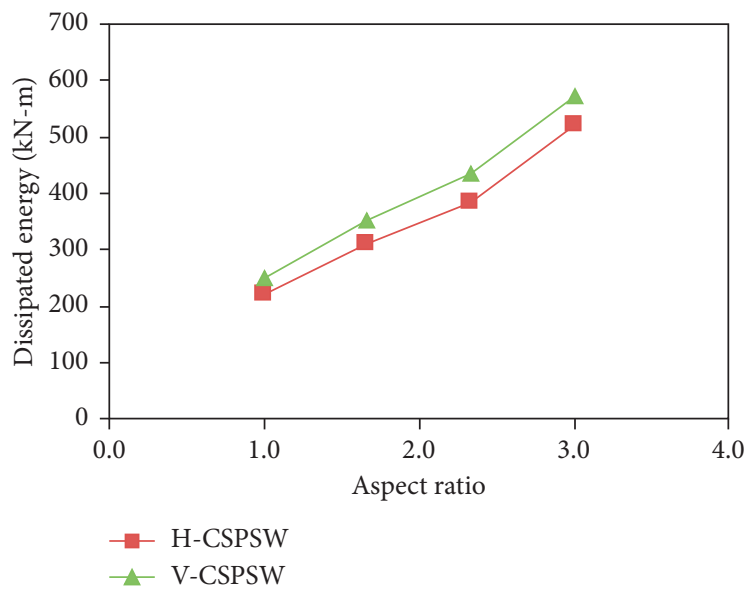

(c)

Figure 18: The responses of H-CSPSW and V-CSPSW as functions of infill plate aspect ratio. (a) Initial stiffness. (b) Ultimate strength. (c) Dissipated energy.

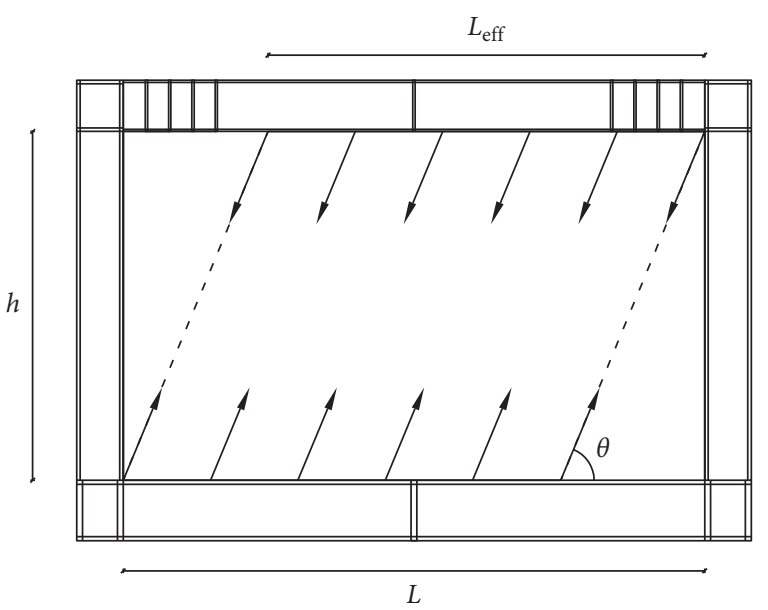

Figure 19: Partial tension field and effective length.

[9]. Therefore, in this study, $F_{p t}$ is calculated through the following equation:

$$
F_{p t}=L t\left(\tau_{c r . \text { in }}^{e}\right)+L_{\text {eff }} t\left(0.5 \sigma_{t y} \sin 2 \theta\right),
$$

where $t$ is the thickness of the infill plate, $\tau_{c r \text {.in }}^{e}$ is the plate interactive shear buckling stress, $\sigma_{t y}$ is the yield stress of the tension field calculated based on von Mises criterion, and $\tau_{c r . i n}^{e}$ is obtained as follows $[15,47]$ :

$$
\left(\frac{1}{\tau_{c r . \mathrm{in}}^{e}}\right)^{2}=\left(\frac{1}{\tau_{c r . L}^{e}}\right)^{2}+\left(\frac{1}{\tau_{c r . G}^{e}}\right)^{2}+\left(\frac{1}{\tau_{y}}\right)^{2},
$$

where $\tau_{y}$ is yielding shear stress. $\tau_{c r . L}^{e}$ and $\tau_{c r . G}^{e}$ are local and global shear buckling stresses which are measured by using the following equations $[15,47]$ :

$$
\begin{gathered}
\tau_{c r . L}^{e}=\left[5.34+4\left(\frac{a}{h}\right)^{2}\right] \frac{\pi^{2} E}{12\left(1-v^{2}\right)}\left(\frac{t}{a}\right)^{2}, \\
\tau_{c r . G}^{e}=\frac{36 \varphi E}{\left[12\left(1-\nu^{2}\right)\right]^{0.25}}\left[\frac{(d / t)^{2}+1}{6 \gamma}\right]^{0.75}\left(\frac{t}{h}\right)^{2},
\end{gathered}
$$

where $E$ is Young's elasticity modulus, $v$ is Poisson's ratio, $h$ is panel height, $\varphi$ is boundary condition factor fluctuating between 1.0 and 1.9 and assumed to be 1.0 in this study, and $\gamma$ is a factor that describes corrugation geometry obtained using the following equation $[15,47]$ :

$$
\gamma=\frac{a+b}{a+c}
$$




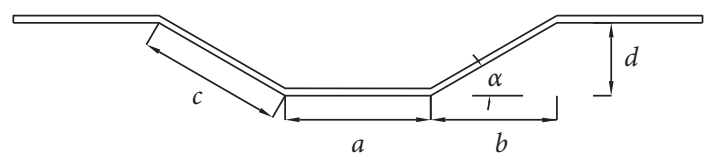

FIgURE 20: Parameters of corrugated panel geometry.

TABle 6: Comparison of the ultimate strength calculated by analytical method and FE analysis.

\begin{tabular}{lccc}
\hline Specimen & $\begin{array}{c}\text { Strength by analytical } \\
\text { method }(\mathrm{kN})\end{array}$ & $\begin{array}{c}\text { Strength by FE } \\
\text { analysis }(\mathrm{kN})\end{array}$ & $\begin{array}{c}\text { Error } \\
(\%)\end{array}$ \\
\hline Horizontal & 462.9 & 503.6 & 8.0 \\
Vertical & 580.1 & 551.4 & 4.9 \\
\hline
\end{tabular}

where $a, b, c$, and $d$ are the corrugated panel geometry parameters given in Figure 20. $\sigma_{t y}$ is the yield tension field stress measured through the following equation [15]:

$$
\sigma_{t y}^{2}+\left(3 \tau_{c r \text {.in }}^{e} \sin 2 \theta\right) \sigma_{t y}+\left(3 \tau_{c r . \text { in }}^{e 2}-\sigma_{y}^{2}\right)=0,
$$

where $\sigma_{y}$ is the yield stress of the steel plate.

The final shear strength of horizontal and vertical CSPSWs with the infill plate thickness value of $1.0 \mathrm{~mm}$ and a panel aspect ratio of 1.67 was measured by an analytical method through equations (1)-(9), and the obtained results were compared with those of finite element (FE) (Table 6). It can be concluded that the proposed analytical equations are able to forecast the ultimate strength of CSPSWs with less than $8 \%$ error. However, the proposed method underestimates the ultimate strength of H-CSPSWs and overestimates the ultimate strength of V-CSPSWs.

\section{Conclusions}

The cyclic performance of Corrugated Steel Plate Shear Walls (CSPSWs) with beam-only-connected infill plates was investigated in this study. Several finite element models were developed and analyzed for parametric studies. Infill plate orientation, infill plate thickness, and infill plate aspect ratio were considered as the main parameters in this performance evaluation. Responses of interest were force-deformation relationship, initial stiffness, ultimate strength, and energy dissipation capacity. The following conclusions drawn from this study are given as follows:

(i) Fully connected horizontal CSPSWs (H-CSPSWs) and vertical CSPSWs (V-CSPSWs) had a similar cyclic performance.

(ii) Releasing columns from infill plate resulted in a reduction in initial stiffness, ultimate strength, and energy dissipation of CSPSWs.

(iii) Detaching columns from infill plate in H-CSPSWs caused a considerable decrease in initial stiffness, ultimate strength, and energy dissipation. However, for V-CSPSW, detaching columns from the infill plate caused a low decrease in responses compared with H-CSPSW. Therefore, beam-only-connected $\mathrm{V}$-CSPSWs were more attractive than beam-onlyconnected H-CSPSWs for practical use. (iv) By increasing infill plate thickness at a panel aspect ratio of 1.67 , initial stiffness, ultimate strength, and energy dissipation were approximately constant for $\mathrm{H}$-CSPSW. However, these responses increased proportionally to the infill plate thickness for V-CSPSW.

(v) Elevation of panel aspect ratio is influential in improving the cyclic performance of the beam-onlyconnected CSPSWs. Simply put, one should use CSPSWs in wider bays.

(vi) The proposed analytical method is able to predict the ultimate strength of CSPSWs with much less than $8 \%$ error.

\section{Data Availability}

Data are available on request to the corresponding author.

\section{Conflicts of Interest}

The authors declare that they have no conflicts of interest.

\section{References}

[1] R. Sabelli and M. Bruneau, Design Guide 20: Steel Plate Shear Walls, AISC, Chicago, IL, USA, 2007.

[2] L. J. Thorburn, G. L. Kulak, and C. J. Montgomery, Analysis of Steel Plate Shear Walls" Structural Engineering Report No. 107, Department of Civil Engineering, University of Alberta, Edmonton, Canada, 1983.

[3] P. A. Timler and G. L. Kulak, Experimental Study of Steel Plate Shear Walls" Structural Engineering Report No. 114, Department of Civil Engineering, University of Alberta, Edmonton, Canada, 1983.

[4] T. M. Roberts and S. S. Ghomi, "Hysteretic characteristics of unstiffened plate shear panels," Thin-Walled Structures, vol. 12, no. 2, pp. 145-162, 1991.

[5] V. Caccese, M. Elgaaly, and R. Chen, "Experimental study of thin steel-plate shear walls under cyclic load," Journal of Structural Engineering, vol. 119, no. 2, pp. 573-587, 1993.

[6] R. G. Driver, G. L. Kulak, D. J. L. Kennedy, and A. E. Elwi, "Seismic Behavior of Steel Plate Shear Walls" Structural Engineering Report No. 215, Department of Civil Engineering, University of Alberta, Edmonton, Canada, 1997.

[7] M. Rezai, Seismic behavior of steel plate shear walls by shake table testing, Ph.D. Dissertation, University of British Columbia, Vancouver, Canada, 1999.

[8] J. W. Berman and M. Bruneau, "Experimental investigation of light-gauge steel plate shear walls," Journal of Structural Engineering, vol. 131, no. 2, pp. 259-267, 2005.

[9] F. Emami, M. Mofid, and A. Vafai, "Experimental study on cyclic behavior of trapezoidally corrugated steel shear walls," Engineering Structures, vol. 48, no. 6, pp. 750-762, 2013.

[10] F. Emami and M. Mofid, "On the hysteretic behavior of trapezoidally corrugated steel shear walls," The Structural Design of Tall and Special Buildings, vol. 23, no. 2, pp. 94-104, 2014.

[11] A. Farzampour, J. A. Laman, and M. Mofid, "Behavior prediction of corrugated steel plate shear walls with openings," Journal of Constructional Steel Research, vol. 114, pp. 258-268, 2015. 
[12] M. Bahrebar, M. Z. Kabir, T. Zirakian, M. Hajsadeghi, and J. B. P. Lim, "Structural performance assessment of trapezoidally-corrugated and centrally-perforated steel plate shear walls," Journal of Constructional Steel Research, vol. 122, pp. 584-594, 2016.

[13] Q. Cao and J. Huang, "Experimental study and numerical simulation of corrugated steel plate shear walls subjected to cyclic loads," Thin-Walled Structures, vol. 127, pp. 306-317, 2018.

[14] C. Dou, Y.-L. Pi, and W. Gao, "Shear resistance and postbuckling behavior of corrugated panels in steel plate shear walls," Thin-Walled Structures, vol. 131, pp. 816-826, 2018.

[15] A. Farzampour, I. Mansouri, C.-H. Lee, H.-B. Sim, and J. W. $\mathrm{Hu}$, "Analysis and design recommendations for corrugated steel plate shear walls with a reduced beam section," Thin-Walled Structures, vol. 132, pp. 658-666, 2018.

[16] M. Bahrebar, J. B. P. Lim, G. C. Clifton, T. Zirakian, A. Shahmohammadi, and M. Hajsadeghi, "Perforated steel plate shear walls with curved corrugated webs under cyclic loading," Structure, vol. 24, pp. 600-609, 2020.

[17] J. Fang, W. Bao, F. Ren, T. Guan, G. Xue, and J. Jiang, "Experimental study of hysteretic behavior of semi-rigid frame with a corrugated plate," Journal of Constructional Steel Research, vol. 174, Article ID 106289, 2020.

[18] S. M. Ghodratian-Kashan and S. Maleki, "Numerical investigation of double corrugated steel plate shear walls," Journal of Civil Engineering and Construction, vol. 10, 2021.

[19] M. Safari Gorji and J. J. R. Cheng, "Steel plate shear walls with outriggers. Part I: plastic analysis and behavior," Journal of Constructional Steel Research, vol. 134, pp. 148-159, 2017.

[20] M. Safari Gorji and J. J. R. Cheng, "Steel plate shear walls with outriggers. Part II: seismic design and performance," Journal of Constructional Steel Research, vol. 137, pp. 311-324, 2017.

[21] D. J. Borello and L. A. Fahnestock, "Seismic design and analysis of steel plate shear walls with coupling," Journal of Structural Engineering, vol. 139, no. 8, pp. 1263-1273, 2013.

[22] R. Purba and M. Bruneau, "Finite-element investigation and design recommendations for perforated steel plate shear walls," Journal of Structural Engineering, vol. 135, no. 11, pp. 1367-1376, 2009.

[23] T. Zirakian and J. Zhang, "Structural performance of unstiffened low yield point steel plate shear walls," Journal of Constructional Steel Research, vol. 112, pp. 40-53, 2015.

[24] K. C. Tsai and C. S. Li, "Experimental responses of four 2-story narrow steel plate shear wall," in Proceedings of the 2008 Structures Congress, pp. 1-10, ASCE, Vancouver, Canada, 2008.

[25] D. Vian, M. Bruneau, K. C. Tsai, and Y.-C. Lin, "Special perforated steel plate shear walls with reduced beam section anchor beams. I: experimental investigation," Journal of Structural Engineering, vol. 135, no. 3, pp. 211-220, 2009.

[26] D. Vian, M. Bruneau, and R. Purba, "Special perforated steel plate shear walls with reduced beam section anchor beams. II: analysis and design recommendations," Journal of Structural Engineering, vol. 135, no. 3, pp. 221-228, 2009.

[27] A. Jahanpour, J. Jönsson, and H. Moharrami, "Seismic behavior of semi-supported steel shear walls," Journal of Constructional Steel Research, vol. 74, pp. 118-133, 2012.

[28] M. Xue and L. W. Lu, "Monotonic and cyclic behavior of infilled steel shear panels," in Proceedings of the 17th Czech and Slovak International Conference on Steel Structures and Bridges, Bratislava, Slovakia, 1994.
[29] I.-R. Choi and H.-G. Park, "steel plate shear walls with various infill plate designs," Journal of Structural Engineering, vol. 135, no. 7, pp. 785-796, 2009.

[30] L. Guo, Q. Rong, X. Ma, and S. Zhang, "Behavior of steel plate shear wall connected to frame beams only," International Journal of Steel Structures, vol. 11, no. 4, pp. 467-479, 2011.

[31] C. Vatansever and N. Yardimci, "Experimental investigation of thin steel plate shear walls with different infill-to-boundary frame connections," Steel and Composite Structures, vol. 11, no. 3, pp. 251-271, 2011.

[32] P. M. Clayton, J. W. Berman, and L. N. Lowes, "Subassembly testing and modeling of self-centering steel plate shear walls," Engineering Structures, vol. 56, pp. 1848-1857, 2013.

[33] P. M. Clayton, J. W. Berman, and L. N. Lowes, "Seismic performance of self-centering steel plate shear walls with beam-only-connected web plates," Journal of Constructional Steel Research, vol. 106, pp. 198-208, 2015.

[34] ABAQUS 6.14.3, ABAQUS 6.14.3 Documentation, Hibbitt, Karlson, Sorenson, Inc., 2015.

[35] Z. Javanbakht, W. Hall, A. S. Virk, J. Summerscales, and A. Öchsner, "Finite element analysis of natural fiber composites using a self-updating model," Journal of Composite Materials, vol. 54, no. 23, pp. 3275-3286, 2020.

[36] 1983 DIN 1623, 1629 International Standard of Germany.

[37] L. Hosseinzadeh, F. Emami, and M. Mofid, "Experimental investigation on the behavior of corrugated steel shear wall subjected to the different angle of trapezoidal plate," The Structural Design of Tall and Special Buildings, vol. 26, no. 17, pp. 1-17, 2017.

[38] H. L. Yu and D. Y. Jeong, "Application of a stress triaxiality dependent fracture criterion in the finite element analysis of unnotched charpy specimens," Theoretical and Applied Fracture Mechanics, vol. 54, no. 1, pp. 54-62, 2010.

[39] F. Hassani and Z. Javanbakht, "Effect of geometrical variations on the failure mechanisms of perforated steel plate shear Walls-a parametric study towards a new design," Thin-Walled Structures, vol. 159, Article ID 107244, 2021.

[40] M. M. Alinia and M. Dastfan, "Behaviour of thin steel plate shear walls regarding frame members," Journal of Constructional Steel Research, vol. 62, no. 7, pp. 730-738, 2006.

[41] M. M. Alinia, S. A. A. Hosseinzadeh, and H. R. Habashi, "Numerical modelling for buckling analysis of cracked shear panels," Thin-Walled Structures, vol. 45, no. 12, pp. 1058-1067, 2007.

[42] A. K. Nasar and S. Gaurav, "Models for strength and stiffness of steel plate shear walls with openings," Structures, vol. 27, pp. 2096-2113, 2020.

[43] Z. Qiuhong, J. Sun, Y. Li, and Z. Li, "Cyclic analyses of corrugated steel plate shear walls," The Structural Design of Tall and Special Buildings, vol. 26, no. 16, Article ID e1351, 2017.

[44] ATC, "Guidelines for cyclic seismic testing of components of steel structures," Report No. 24, Applied Technology Council, Redwood City, CA, US, 1992.

[45] AISC, Seismic Provisions for Structural Steel Buildings, American Institute of Steel Construction, Chicago, IL, US, ANSI/AISC 341-16, 2016.

[46] ATC, "Modeling and acceptance criteria for seismic design and analysis of tall buildings," Report No. 72, Applied Technology Council, Redwood City, CA, USA, 2010.

[47] J. Yi, H. Gil, K. Youm, and H. Lee, "Interactive shear buckling behavior of trapezoidally corrugated steel webs," Engineering Structures, vol. 30, no. 6, pp. 1659-1666, 2008. 